\title{
Systematic ichnology of the Mabou and Cumberland groups (Carboniferous) of western Cape Breton Island, eastern Canada, 2: surface markings
}

\author{
Dave G. Keighley* and Ron K. Pickerill \\ Department of Geology, University of New Brunswick, Fredericton, New Brunswick E3B 5A3, Canada
}

Date Received July 17, 1997

Date Accepted February 9, 1998

\begin{abstract}
Carboniferous (Namurian-Westphalian A) strata of the Mabou and Cumberland groups outcrop extensively in western Cape Breton Island. As well as a diverse collection of burrows, trails, pits, and coprolites described previously, numerous surface marks, mostly trackways, were encountered in these strata: Diplichnites cf. logananus (Marsh), Diplichnites isp. (types A and B), Gluckstadtella cooperi Savage, Hexapodichnus horrens Hitchcock, Monomorphichnus cf. lineatus Crimes et al., Protichnites cf. carbonarius Dawson, Protichnites cf. kennediea (Smith), Protichnites cf. scoticus Salter, Protichnites cf. variabilis (Linck), Protichnites isp. (types A, B, C, and D), Stiallia cf. pilosa Smith, Appendage Marks (types A and B), an "Arthropod Resting" Trace, Horn-shaped Surface Traces, and Vertebrate Trackways (types A, B, C, D, E, and F).
\end{abstract}

Des strates du Carbonifère (Namurien-Westphalien A) des groupes de Mabou et de Cumberland affleurent sur une surface étendue dans l'ouest de l'île du Cap-Breton. On relève en outre dans ces strates une collection diversifiée de terriers, de pistes, de trous et de coprolites décrits antérieurement; un grand nombre de marques au sol, en majeure partie des pistes, comme celles du Diplichnites cf. logananus (Marsh), du Diplichnites isp. (types A et B), du Gluckstadtella cooperi Savage, de l'Hexapodichnus horrens Hitchcock, du Monomorphichnus cf. lineatus Crimes et colll., du Protichnites cf. carbonarius Dawson, du Protichnites cf. kennediea (Smith), du Protichnites cf. scoticus Salter, du Protichnites cf. variabilis (Linck), du Protichnites isp. (types A, B, C et D) et de la Stiallia cf. pilosa Smith, des marques d'appendices (types A et $B$ ), une trace " $d$ 'arthropode au repos", des traces en surface en forme de corne et des pistes de vertébrés (types $A, B, C, D, E$, et F).

[Traduit par la rédaction]

\section{INTRODUCTION}

This paper describes and discusses several of the trace fossils encountered at various localities in western Cape Breton Island (Fig. 1). The numerous surface markings described (primarily tracks and trackways) occur in Carboniferous (NamurianWestphalian A) Mabou and Cumberland Group strata that have been confidently inferred to be the products of fluvial, floodplain, and lacustrine sedimentation in half grabens maintained by a transtensional tectonic regime (Keighley and Pickerill, 1996a). The surface markings may occur exclusive of, or associated with, the trace fossils already described from these strata by Keighley and Pickerill (1997); Baird (personal communication, 1989, 1994) and his co-workers have collected additional material that remains undescribed. Future work will assess the palaeoenvironmental distribution of our specimens.

\section{NOMENCLATURAL PROBLEMS AND TERMINOLOGY}

Before presenting our taxonomic classification of the trace fossils from the study area, it is necessary to first comment on the chaotic taxonomic nomenclature that exists for both

-Current Address: Department of Earth Sciences, University of Liverpool, Brownlow Street, Liverpool, England, L69 3BX vertebrate and invertebrate trackways and explain the principles behind our nomenclatural decisions. As stated in Keighley and Pickerill (1996b, 1997) and Pickerill and Keighley (1997), an ichnotaxon can only be formally named (and hence diagnosed) from distinguishing morphological features, following the guidelines of the International Code of Zoological Nomenclature (I.C.Z.N., 1985). Criteria such as (a) the phylogeny of the producer, (b) stratigraphic limitation of the trace fossil, or (c) the environment in which the trace fossil was produced, are not criteria that can be directly, or objectively, observed or proven in a type specimen. Therefore they remain hypothetical concepts and so cannot be used to provide a name based upon the 'Principle of the Name-bearing Type' (I.C.Z.N., 1985, p. xiii, Article lb-1). Specifically, for a name now to be available, it must upon introduction include a description of characteristics that purport to make the (trace-) fossil unique (I.C.Z.N., Article 13a-i), which the above criteria cannot conclusively provide. Sarjeant and Kennedy (1973), Sarjeant (1975, 1990), and Magwood (1992), amongst others, have also provided excellent and compelling reasons for rejecting such criteria in favour of a morphologically based nomenclature. Sarjeant (1990) further noted that there is nothing to prevent use of parallel names based on systematic affinity where the investigation being undertaken requires such a 


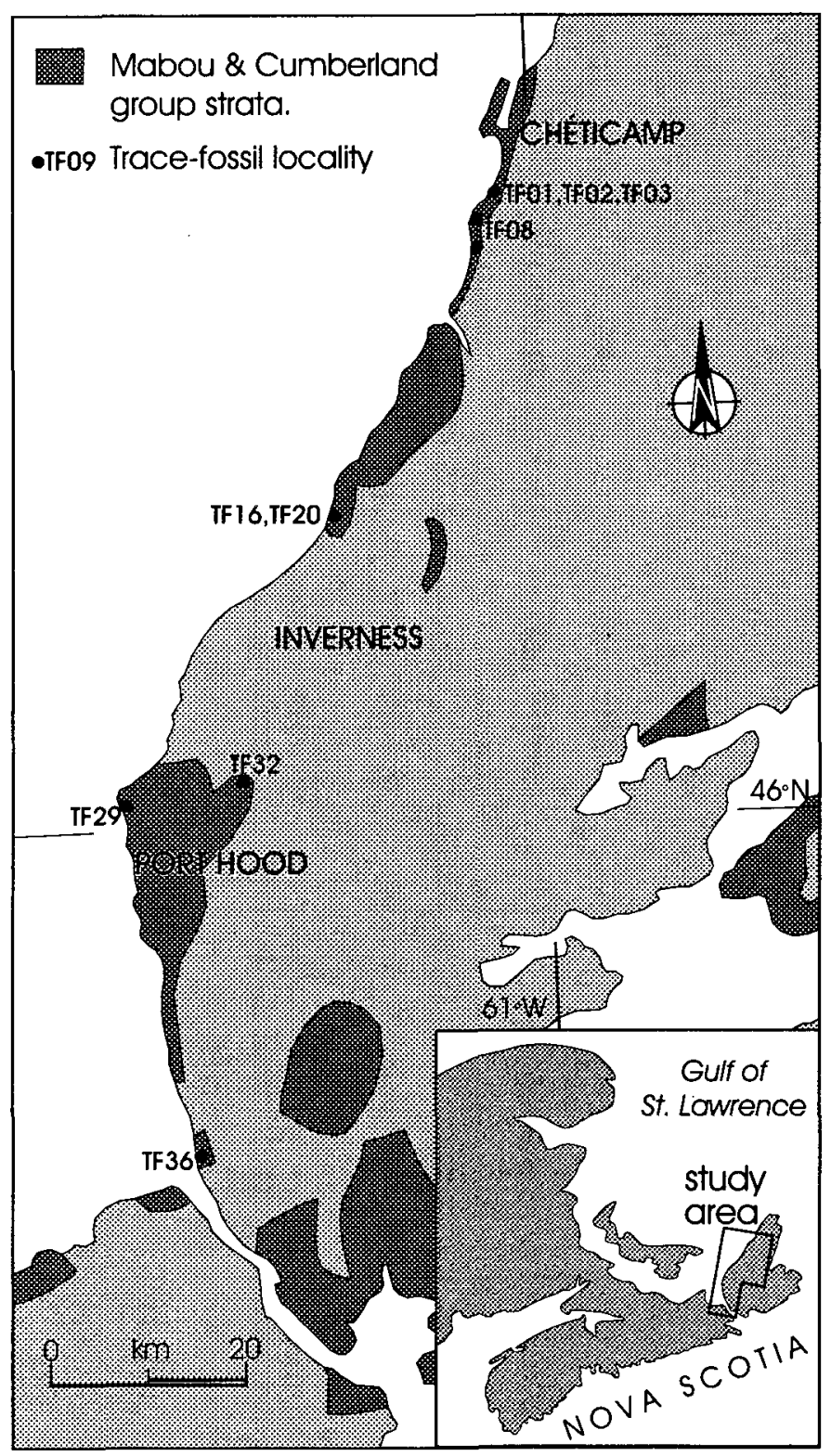

Fig. 1. Location map of trace-fossil localities within the Mabou and Cumberland groups in western Cape Breton Island.

classification. However, such names cannot compete with morphological nomenclature or be regulated by the I.C.Z.N. for reasons outlined above.

Unfortunately, many trace fossils were originally named prior to the existence of a nomenclatural code, and numerous others were published in the period 1961 to 1985 when the I.C.Z.N. inadvertently ruled that trace-fossil names first published after 1930 were not available (see Pickerill, 1994, for discussion). Accordingly, workers during these periods were not bound by formal regulations and so were free to utilize non-morphological criteria.

Another nomenclatural problem is the lack of uniformity as to which morphological features should be adopted as being diagnostic of an ichnotaxon. Fürsich (1974) suggested that ichnogenera be formulated, or revised, based upon morphological features resulting from what is interpreted to be behaviour at a high level of significance (significant features), and ichnospecies from features considered to result from behaviour of less importance (secondary features). Such interpretations of significant behaviour are highly subjective and, futhermore, morphological terminology itself is not covered by the I.C.Z.N. or any other code. Accordingly such terms often have different definitions attached to them, resulting in nomenclatural confusion. For clarity, therefore, our use of crtain morphological terms follows Keighley and Pickerill (1997) and the definitions below.

A 'trackway' is herein defined as a succession of individual marks that collectively form a ribbonlike structure at a sedimentary (or, potentially, an extrusive igneous) interface (in contrast, a trail represents a continuous mark left on the substrate: no separate marks are preserved-Trewin, 1994). A trackway should be characterized by two 'rows' of imprints, or two 'track rows' (or, interpretively, two rows of appendage marks, Fig. 2A). Typically the rows would represent records of both the left- and right-sided appendages of an animal that were produced while supporting itself above the substrate during locomotive activity, since almost all animals known to be capable of such locomotion have bilateral symmetry. If it cannot be determined whether two rows of imprints are present, then they can simply be described as a sequence of 'tracks' (Fig. 2). The shapes of individual prints also varies, and the terminology we use is given in Figure 2B. Within a row, a 'natural track cycle' (Anderson, 1975) contains a single imprint from each of the producing appendages (but that may include imprints of separate digits extending from one appendage) from one side of the body (Fig. 2C-this term is preferred to Trewin's 'imprint series').

Essentially, only two phylogenetic groups, the vertebrates and arthropods, produce trackways (but vagile Echinodermata are a potential exception, and need not have bilateral symmetry either, e.g., Sutcliffe, 1997). Trackways formed by vertebrates can usually be distinguished from those produced by invertebrates, primarily by their form and geometry. Thus, when the qualifiers 'vertebrate' or 'invertebrate' are applied to a trackway, they are used more in a descriptive rather than interpretive sense. However, use of such qualifiers has had its pitfalls. As detailed below, several trackways previously interpreted as vertebrate in affinity are now considered to be invertebrate in origin.

Terminology for vertebrate trackways mostly follows Leonardi (1987). The front print of repeated, longitudinally in-line couplets of prints is typically regarded as the manus (forefoot), as is the inner print of diagonally or transversely in-line couplets, or the smaller print of the couplet. However, in some cases where similar sized, longitudinally in-line prints are present (e.g., Sarjeant, 1975, p. 290, fig. 14.6), or where preservation is poor, decisions regarding which prints reflect the manus, and which reflect the pes (backfoot) have been relegated to comments within the remarks, since in the studied examples they are invariably interpretive decisions. Accordingly, we number prints within a trackway simply, on the left-hand side ('left side') of the trackway, L1, L2, L3, etc., and on the right-hand side ('right side') R1, R2, R3, etc. 


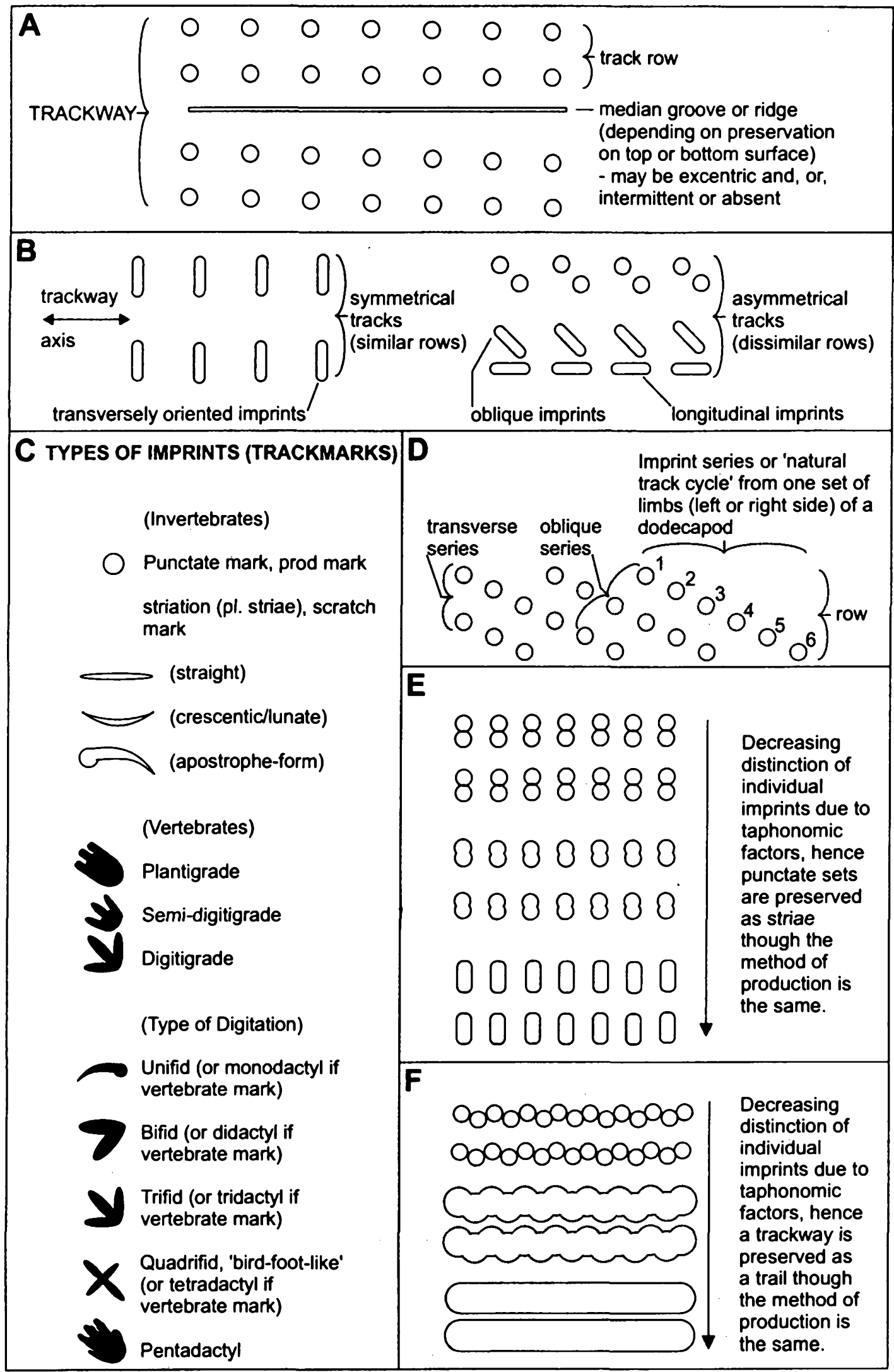

Fig. 2. General terminology and preservation of tracks and trackways (adapted from Anderson, 1975; Trewin, 1994). A, B = General terminology of a trackway. The series noted would be termed a transverse series. Other series are possible (as shown in D). Repeated series occur longitudinally along the trackway and form a row. C = Types of track marks. Note that Trewin's (1994) 'trifid' mark we would consider to be 'quadrifid'. $\mathrm{D}$ = Series and natural track cycles. Only the natural track cycle, a special type of series, includes one imprint of each appendage on one side of the producer. $E=$ Preservational variation may result in individual marks not being preserved. The appearance may be of one striate mark, whereas it was actually produced by two, merged, punctate marks. $F=$ Preservational variation may result in individual marks not being preserved. What was originally produced as a trackway may be preserved as a trail. 


\section{TAXONOMIC DISCUSSION}

We have been unable to access much of the relevant type material and so a thorough discussion, and formal revision, of taxonomic problems is not attempted herein. The following comments only provide an explanation of our choice of names for the western Cape Breton material, based upon the adoption of I.C.Z.N. procedures regarding synonymous ichnotaxa-primarily the 'Principle of Priority' (I.C.Z.N., 1985, Article 23; and see discussion in Keighley and Pickerill, 1996c) and the 'Stability of Usage' (I.C.Z.N., 1985, Article 23b). However, as advocated by Goldring et al. (1997), synonymy is not extended to include potential taphonomic and toponomic variants of specific ichnotaxa.

In many cases, the taxonomical problems of invertebrate and vertebrate trackways have stemmed from a worker's desire to either provide a new name for every slight morphological variation in trackway form (e.g., Holub and Kozur, 1981, introduced sixteen new ichnogenera and nineteen new ichnospecies; Walter, 1983, introduced sixteen new ichnogenera and thirty-four new ichnospecies), or allocate a trace or suite of traces to a particular zoological grouping such as a phylum, class, or family (e.g., Fischer, 1978, provided a complete classification of invertebrate trackways based on the biological nature of the producer). Following from our earlier comments, the latter procedure can now be seen as invalid, but the former procedure is valid though of debatable utility because the morphological variations encountered in trackways are enormous. For example, the invertebrate trackway diagrammatically illustrated in Figure $2 \mathrm{~A}$ could, alternatively, have contained (a) sets of one, two, three, or more, striate, and, or, punctate imprints that may be (b) unifid (apostrophe-form), bifid, trifid, and, or, quadrifid, and (c) transversely, obliquely, and, or, longitudinally oriented. Morphology will also vary when (d) rows differ, thus forming an asymmetrical trackway (sensu Trewin, 1994), and (e) if the trackway has or has not a continuous or discontinous, singular or multiple groove.

The factors that can influence the observed morphology of a trackway are also varied and include: (i) the actual morphology of the producer (e.g., number of appendages), (ii) very slight variations in the behaviour of a trackway maker, such as whether the producer made a straight or curved path (e.g., Walker, in Briggs et al., 1984) and whether the producer moved quickly or slowly (e.g., Crimes, 1970; Sarjeant, 1990), (iii) whether the producer moved along flat ground or up, across, or down a slope (e.g., Brand, 1979), together with the firmness or consistency of the substrate that was crossed (e.g., Brady, 1947; Brand, 1979, 1996), (iv) toponomy, and (v) preservation. In factor (iv), undertracks may be distinctly different in morphology from their surface expression, influenced by different depths of penetration by individual appendages, and the surface area each appendage covered when it was in contact with the substrate (Goldring and Seilacher, 1971).

It could be argued that factors (ii) and, more indirectly, (iii) and (iv) lead to morphological features based on ethology (e.g., moving on dry sand slowly uphill, or wet sand quickly downhill) and all such features are worthy of being either primary or secondary ichnotaxobases. If all these fea- tures are used, the result is a multitude of potential ichnotaxobase combinations and a plethora of potentially valid ichnotaxa, with very tight constraints as to each of their diagnoses. This can then lead to an ichnotaxonomically multicompound specimen; for example, where an individual tracemaker, over one short journey, encounters variation in slope and substrate consistency and changes speed and direction irregularly. In a thinly laminated rock, on which the trackway may be preserved, a further profusion of ichnogenera may accompany various levels of undertracking, and differential weathering of the preserving stratum may produce even further variation (whereby taphonomic factors act to alter a trace fossil's morphology and make it resemble a different ichnotaxon-a taphoseries variant-see MacNaughton and Pickerill, 1995).

As previously noted, there have never been formal guidelines as to what morphological ichnotaxobases should be adopted. In order to keep the number of ichnotaxa within reasonable bounds, we believe the choice of primary ichnotaxobases should, therefore, be based on finite criteria and, where possible, avoid the placement of diagnostic boundaries in characteristics that are gradational.

We concur with McKeever and Haubold (1996) that the optimal state of preservation should be used for principal diagnoses. Specimens with suboptimal preservation can then be named as toponomic and taphonomic variants, following the suggestions of Sarjeant (1990), Goldring et al. (1997) and Keighley and Pickerill (1997). For 'vertebrate' trackways, criteria such as the maximum number of digits present on the manus and pes, relative sizes of manus and pes (cf. McKeever and Haubold, 1996), and most fundamentally, the presence or absence of a manus (i.e., biped or tetrapod) are probably the best primary ichnotaxobases. In avoiding gradational criteria, trackway width and pace angulation pattern would be considered less suitable criteria (McKeever and Haubold, 1996).

Some of the procedures already adopted for 'invertebrate' trackways by Seilacher (1955), and since followed by numerous authors (e.g., Glaessner, 1957; Bergström, 1976; Bromley and Asgaard, 1979), also have considerable merit with respect to I.C.Z.N. guidelines. Seilacher's (1955) suggestion was that, for 'invertebrate' trackways, the presence or absence of a median groove (or ridge, depending on epichnial or hypichnial preservation) was the primary ichnogeneric criterion in distinguishing invertebrate-trackway ichnotaxa. Though it has little ethological importance, it is a distinctive feature, and a finite statement can be made as to whether it is present, sporadically or continuously, or absent. Accordingly, Seilacher (1955) provisionally 'lumped' trackways containing a median groove(s) into Protichnites Owen, and all trackways lacking a median groove into Diplichnites Dawson.

The suggestion to assign such material to Protichnites is compatible with the Principle of Priority. Protichnites appears to have been the first ichnogeneric name used in the literature for indisputably invertebrate trackways (Ichnites having been a general term introduced for all track marks and trackways by Hitchcock, 1837). Owen (1852) did not provide an ichnogeneric diagnosis, but all his material was similar in having rows of more-or-less punctate imprints about a central, linear mark (groove or ridge, depending on top or bottom 
surface preservation). His six ichnospecies were differentiated partly on the number of prod marks per repeated natural track cycle, and the angle that they subtended with the central linear mark (e.g., not fewer than seven marks, arranged in transverse to slightly oblique series of three, two, and two, in $P$. septemnotatus Owen, the type ichnospecies). Individual imprints varied in size but remained generally punctate in shape. Owen (1852) was conscious of the fact that the number of imprints did not necessarily indicate the number of appendages on each side of the vagile producer; some of the imprints could have been made by the same, bifid or trifid, limb. He made several suggestions as to the nature of the producing organism, but favoured a limulid. Subsequently, $P$. scoticus Salter was introduced for much smaller trackways that contained two or three imprints per transverse series on each side of the median ridge in repeated natural track cycles of up to six imprints. It was emphasized that '...the imposition of this generic name does not in any way imply that the creature which made the track was generically identical with those which produced the tracks in the Potsdam sandstone [described by Owen]...' (Salter, in Harkness, 1856, p. 243).

No additional trackway ichnotaxa were apparently described in the literature until Hitchoock (1858) introduced several new ichnogenera for morphologically quite diverse trackways, all of which lacked a median groove. Accordingly, Protichnites was a name used at the ichnogeneric level, prior to the introduction of any other formal name, for trackways (a) containing a median groove, (b) having repeating track cycles of variable number (but essentially of five or more) and that occured en echelon, resulting in transverse series of as few as two, (c) containing individual tracks that were typically punctate (variably circular, ellipsoidal, elongate, or tapered in the terminology of Trewin, 1994), and from unifid, bifid, trifid, or quadrifid appendages, (d) of variable size, and (e) not definitively assigned to any one producer-vertebrate or invertebrate. Note, however, that following Hitchcock's (1858) work, $P$. logananus Marsh was introduced for trackways that lacked a median groove, and thus (following the nomenclatural acts of Hitchcock, 1858, noted above) was inconsistent with an ichnospecies of Protichnites.

One of Owen's (1852) secondary ichnotaxobases was the number of imprints in a natural track cycle, a criterion also used by Salter (in Harkness, 1856). Accordingly, the natural track cycle in $P$. octonotatus Owen was apparently eight, in $P$. septemnotatus, seven, and in $P$. scoticus, six (this is contra Walker, 1985, who stated that the number of imprints in Protichnites and Paleohelcura Gilmore was three-three is the common number in oblique series rather than in a natural track cycle, although in $P$. lineatus $O$ wen, the number in oblique series may be greater). Though of little ethological value, but of potential use in providing a phylogenetic interpretation, the criterion has merit: the maximum number of imprints in a natural track cycle can never exceed the total number of 'walking' appendages (or digits on these appendages) present on one side of the producer, and a finite statement can be made with regards to the maximum number of imprints in a natural track cycle. Thus a trackway may be infinitely variable in morphology along its length, but in treating the differ- ent morphologies as part of a taphoseries (sensu MacNaughton and Pickerill, 1995), the trackway can be named after the morphology from 'highest' (i.e., with maximum number of imprints in a natural track cycle) within the taphoseries.

Subsequent to these earliest works, a multitude of new trackway ichnotaxa have been formulated, including new ichnogenera for trackways exhibiting a median groove. However, the distinction of several of these ichnotaxa relied on proposed ichnotaxobases that can be considered invalid by our earlier comments. For example, and contra Salter's (in Harkness, 1856) statement quoted earlier, the phylogeny of the Protichnites producer was suggested as a primary ichnotaxobase. Dawson (1862) noted that trackways similar to Protichnites were produced by the king crab, Limulus. Accordingly, Packard (1900a) introduced Ostrakichnites as a replacement name for Protichnites carbonarius Dawson, because he considered that $P$. carbonarius could not have been made by a fully grown limulid ( $P$. carbonarius had been introduced in 1873 for small trackways whose imprints were grouped in rhomboidal sets either side of a median groove). Dawson's ichnospecies, by way of the arrangement of the individual marks in a rhomboidal manner, was certainly a novelty with respect to other Protichnites ichnospecies, but the morphology was still within the existing boundaries of the ichnogenus.

Protichnites carbonarius is similar in form to another problematic ichnotaxon, Ichnites lithographicus Oppel, which earlier had been introduced for trackways containing quadrifid imprints and unifid punctate imprints on both sides of a median groove. There is no indication that Oppel (1862) knew of Owen's earlier work and hence whether any subdivision of trackways with median grooves into different ichnogenera was intended, or whether I. lithographicus was introduced merely as a new type of trackway under the general heading of Ichnites, sensu Hitchcock (1837). Kouphichnium Nopsca was subsequently introduced for the trackways of Coelurid reptiles, with $K$. lithographicum (Oppel) included as the type. Following Caster (1939) and Nielsen (1949), these trackways were reinterpreted as the work of Xiphosurids, and numerous other ichnogenera were noted as synonymous. However, subsequent workers again overemphasized the connection of trackway and potential producer. After interpreting their trails to be the result of Xiphosurids, such workers named their tracks Kouphichnium (e.g., Hardy, 1970). Kouphichnium was thus noted to be distinctly polymorphic by Häntzschel (1975). For example, in contrast to $K$. lithographicum, $K$. gracilis Linck contains bifid and quadrifid tracks and lacks a central groove, and $K$. rossendalensis Hardy is a classic example of a compound specimen, the bilobate to ungulate part of the trace now being included by Romano and Whyte (1987) in Selenichnites Romano and Whyte as $S$. rossendalensis (Hardy).

Accordingly, Kouphichnium was introduced solely on the grounds of an interpretation that the trackways were of a particular (dinosaur) producer (Nopsca, 1923), which as previously stated, is an invalid nomenclatural procedure. Subsequently the name has been used based on material distinguished exclusively on an interpretation of a particular (Xiphosurid) producer, and for polymorphous material. Such material would be better included in ichnotaxa introduced with 
morphological ichnotaxobases. Particularly, the material containing a median groove (e.g., $K$. lithographicus) could be incorporated within Protichnites, alongside $P$. carbonarius. It should also be pointed out to workers who advocate use of an interpreted producer or geological age in the naming of trace fossils that, if such considerations were utilized, Kouphichnium would again be synonymous with Protichnites, since Owen's (1852) preferred interpretation for a producer was a limulid, whose ancestors are now known to extend back to the Cambrian (Clarkson, 1993)!

Trackways with either an intermittent median groove or more than one median groove were originally described as Protichnites octonotatus or $P$. alternans Owen and subsequently as such, for example, by Birkenmajer and Bnton (1971). Both traits have also been considered as primary ichnotaxobases of Siskemia Smith; Danstairia Smith, partim; Tarsichnus Walter, partim; Euproopichnus Walter; and Mitchellichnus Walker. Although these latter ichnogenera may have been established on morphological grounds, they have to be considered junior synonyms because their primary ichnotaxobases are already incorporated within the previously established diagnosis of Protichnites and, specifically, the two aforementioned Protichnites ichnospecies. If intermittent or multiple grooves are to be considered (primary) criteria warranting separate ichnogenera, rather than (secondary criteria defining) separate ichnospecies (the latter being the treatment we advocate), then a systematic review of such trackways is necessary that shows how a change in what is permissible for assignment to Protichnites affects the synonymy of other material previously assigned to Protichnites (i.e., into which ichnotaxon should be placed other specimens previously described as Protichnites that preserve intermittent or multiple grooves).

Other ichnogenera have also been introduced or retained on morphological grounds. In the case of Paleohelcura, the number of imprints in a natural track cycle has been fairly conclusively observed to number only three. In Stiaria Smith, the number of imprints was stated to number between two and four (Walker, 1985), and Paleohelcura was thus considered its junior synonym by Pollard and Walker (1984). Since Stiaria would have a natural track cycle of four, Paleohelcura is not synonymous, but whether either or both should be considered acceptable at the ichnogenus level is debatable. Since trackways with natural track cycles of six, seven, and eight are included within Protichnites, it is inconsistent to have separate ichnogenera for trackways with natural track cycles of three and four. The latter morphologies would be better included as separate ichnospecies of Protichnites (and in the case where the maximum number of tracks is not clearly evident, assignment can simply be to 'Protichnites' isp. rather than questionably and subjectively to one of Paleohelcura, Protichnites, or Stiaria). Walter's (1983) introduction of Euproopichnus for trackways with natural track cycles of six punctate imprints arranged obliquely, does not adequately distinguish it morphologically from its suspected senior synonym, P. scoticus.

In contrast to Seilacher's (1955) recommendation to 'lump' all 'invertebrate' trackways with median grooves into Protichnites, which, as shown, has considerable historical merit, the case for using Diplichnites as a name for all 'invertebrate' trackways that lack a central groove is highly problematical. As already noted, the most senior names for trackways lacking median grooves were suggested by Hitchcock (1858, 1865) and so the use of Diplichnites for all trackways lacking a median groove does not follow the I.C.Z.N.'s Principle of Priority. Many of Hitchcock's (1858) ichnotaxa might have been considered 'forgotten names' but for the redescription of his collections by Lull $(1915,1953)$-only synonymous ichnotaxa first described between the years 1908 and 1915 could strictly overturn use of Hitchcock's names (I.C.Z.N., Article 79c). Alternatively, a case might exist for applying I.C.Z.N., Article 23b, that allows stability of usage to overturn priority (e.g., Osgood and Drennen, 1975). In a non-exhaustive literature review, Diplichnites was encountered in over sixty articles, in contrast to the next most commonly used name, Merostomichnites, that has been used in less than twenty-Hitchcock's $(1858,1865)$ ichnogenera have been used in less than ten. Unfortunately, stability of usage is not demonstratable.

In contrast to the approach of Owen (1852), who permitted considerable morphological variation within Protichnites, Hitchoock $(1858,1865)$ introduced numerous ichnogenera, some of which were differentiated on very minor variations in form. Although most of his ichnogenera must be considered validly introduced names based upon their initial morphological descriptions, he later clouded their distinction (Hitchcock, 1865) by including specimens exhibiting characteristics of one ichnogenus within another. For example, Acanthichnus Hitchoock was characterized by having oblique to longitudinally oriented striae with no indication of a natural track cycle. However, new specimens that locally indicated a natural track cycle of three were later included (Hitchcock, 1865, unpaginated, pl. 6.1) within the type ichnospecies, $A$. cursorius Hitchcock. These new tracks were actually excellent specimens for demonstrating the potential variation in trackway form over a short distance. Hitchcock's (1865) later material was noted to make Acanthichnus similar to Lithographus Hitchcock, Hexapodichnus Hitchcock, Grammepus Hitchcock, and Copezia Hitchcock (these other ichnotaxa had been differentiated on the basis of the varying orientations, mostly oblique to longitudinal, of the three imprints relative to one another). Furthermore, one ichnospecies of Acanthichnus, A. tardigradus Hitchcock, was subsequently transferred to a new ichnogenus, Pterichnus Hitchoock, solely because the trackway more closely resembled that produced by a myriapod than an insect (all of the above named ichnotaxa of Hitchcock, 1858, were considered the work of insects). Re-examination of the type material might confirm that all the forms can be accommodated within, perhaps, two ichnogenera (e.g., Acathichnus or Hexapodichnus for symmetrical, striate trackways, and Ptilichnus for trackways with dissimilar rows) depending upon what primary ichnotaxobases were to be retained. Regardless of how many ichnogenera are retained, ultimately, they would have to be considered potential senior synonyms to all other trackways having primarily striate imprints and lacking a median groove.

Subsequent ichnogenera have been introduced for trackways with distinct natural track cycles comprising three imprints, but lacking a median groove. Numerous ichnospecies 
of Heterotripodichnus Walter display a variety of arrangements of the three imprints (see Walter, 1983, p. 186, figs. V.10, V.13; p. 187, figs. VI.2, VI.3, VI.7; p. 188, fig. VII.1). However, other ichnospecies of Heterotripodichnus have four imprints (e.g., H. medioimpressus Walter, 1983, figs. VI.6, VII.13) or possibly more (e.g., $H$. marginodigitatis Walter, 1983, figs. VI.4, VII.3). These morphological inconsistencies were further compounded by Walter's (1983) other nomenclatural decisions. Tarsichnus contained both T. kommatus Walter with three or possibly four (generally punctate) imprints in a variably arranged natural track cycle without a median groove, and T. tripedalis Walter with the same number of imprints, variably arranged, and a median groove. In contrast, Etterwindichnus Walter is illustrated as having a natural track cycle of three punctate marks arranged in oblique series. Furthermore, he also included within Permichnium Guthorl (which has a natural track cycle of two) the more senior ichnotaxa Hamipes Hitchcock and Bifurculipes Hitchcock (that also have natural track cycles numbering two), and Hexapodichnus (natural track cycle of three), yet Lithographus (natural track cycle of three) was retained as a distinct ichnotaxon.

It might be wise to consider the number of imprints as a primary ichnotaxobase, with their arrangement as a secondary ichnotaxobase, as Walter (1983) appears to have accepted, in part, for Heterotripodichnus. However, if this were to be done for morphological classification of his trackways, all the material should be included in the most senior name given in Walter's (1983) synonymy, namely Lithographus-which, incidentally, Hitchcock (1865) considered a synonym of Copezia. On morphological grounds, Walter (1983) should not have introduced new ichnotaxa (I.C.Z.N., Articles 17, 23d). Similarly, the inclusion of 'four footed' ichnogenera within Permichnium disregards the Principle of Priority which would have either Hamipes or Bifurculipes as the senior synonym.

Diplichnites was not introduced until Dawson's (1873) work, and problems exist in that the holotype was not particularly well illustrated or described, and the type cannot now be located. It is therefore uncertain whether the type consists of rows of parallel, transverse striae, which Dawson's (1873) description and illustration certainly imply, or of rows of merging punctate imprints arranged in transverse series (e.g., as illustrated in Fig. 2D). Accordingly, the name could be a candidate for synonymy with, for example, Lunula Hitchcock that comprises transversely oriented, slightly lunate, parallel striae.

Diplichnites has subsequently been adopted for both morphologies described above, as well as for rows containing en echelon series of punctate imprints, namely $D$. gouldi (Gevers et al.) and D. cuithensis Briggs et al. This latter morphology has also been described as Trachomatichnus Miller, although Osgood and Drennen (1975), following Seilacher (1955), considered the name synonymous with Diplichnites. More sparsely distributed subcircular to apostrophe-form imprints, exhibiting variably en echelon series (natural track cycles?), have been named, for example, as Merostomichnites narragansettensis Packard, Acripes leavitti Matthew, and Maculichna Anderson, as well as Protichnites logananus. Transverse, tapering to near striate imprints have also been included within Merostomichnites strandi Stormer by Stormer (1934) and by Häntzschel (1975), and within Maculichna by
Aceñolaza and Buatois (1993 - an intermittent median groove also being recorded).

The use of Merostomichnites for trackways is contentious. Packard (1900a) initially described trackways that comprised rows of distinct oval to crescentic imprints in single (or rare oblique double) series as a new ichnospecies of Protichnites, namely $P$. narragansettensis, comparing it to $P$. octonotatus and $P$. logananus. Subsequently, Packard (1900b) introduced Merostomichnites, including within the ichnogenus M. narragansettensis (nom. transl.), and a previously undescribed form, M. beecheri Packard. However, M. beecheri consists of what appear to be stacked, bow-shaped marks (Packard, 1900b, p. 69, fig. 5), and was selected as the type ichnospecies by Hăntzschel (1962). Since polymorphous material cannot be included within the same ichnotaxon (otherwise the name provided would not then convey a unique, precise meaning-I.C.Z.N. Introduction, p. xiii), Merostomichnites should be restricted to trails similar in form to $M$. beecheri (e.g., as illustrated by Fischer, 1978; and as stated by Walter, 1986). All other ichnospecies previously included in Merostomichnites are true trackways and must therefore be included in another ichnotaxon. For example, $M$. triassicus has already been included within Diplichnites by Bromley and Asgaard (1979)a decision followed by Pickerill (1992). Indeed, the only difference between Protichnites logananus (which, as previously argued herein, is better included as 'Diplichnites' logananus) and M. narragansettensis noted by Packard (1900b) was that the latter ichnotaxon was probably the work of a limulid whereas the former ichnotaxon was thought to be the work of a trilobite. As stated previously, such phylogenetic distinctions are not considered to be viable ichnotaxobases or valid nomenclatural acts.

Although Seilacher (1955) and Häntzschel (1962), amongst others, had previously included Acripes within Diplichnites, Pollard (1985) followed Walter (1983) in retaining Acripes, and placed $M$. triassicus within Acripes as $A$. triassicus. The reasoning was that Acripes could not have been formed by a merostome (itself an action that from our earlier comments cannot now be considered an acceptable ichnotaxonomical procedure). Walter (1986) and Demathieu et al. (1992) also chose to retain Acripes.

A further problem exists because of Seilacher's (1955) introduction of Dimorphichnus for trackways with dissimilar rows that lacked a median groove. This was done in the same publication as the recommendation that Diplichnites be used for all trackways lacking a median groove. Consequently, Fillion and Pickerill (1990) suggested restricting Diplichnites to trackways consisting of similar rows of punctate to striate (striae being transversely oriented), regularly spaced imprints.

On this basis, Acripes, by way of the type ichnospecies $A$. incertipes (actually by original designation in Matthew, 1910, p. 124, and not by Häntzschel, 1962-I.C.Z.N., Article $68 \mathrm{~b}$.i) that exhibits considerable heterogeneity between rows, should not be included within Diplichnites. However, this heterogeneity feature had been adopted earlier in the diagnosis of Petalichnus Miller and initially in Ptilichnus, making Dimorphichnus, Acripes, and Petalichnus potential synonyms of Ptilichnus. The dissimilarity of track rows does not extend to all other ichnospecies of Acripes that are candi- 
dates for synonymy within 'Diplichnites'. For instance, $A$. leavitti is essentially identical to Diplichnites logananus for most of its length.

The outcome of Fillion and Pickerill's (1990) modification to the use of Diplichnites is that most of Hitchcock's (1858, 1865) trackway ichnotaxa are not synonymous with it, either because they do not contain similar rows, such as Ptilichnus, or that they do not contain regularly spaced punctate to transversely oriented striate imprints, such as Hexapodichnus. However, the question remains open, pending review of the type material, as to which of Hitchcock's $(1858,1865)$ ichnotaxa should be considered synonymous with one another.

Accordingly, in the description of 'invertebrate' trackways that follows, historical precedence is followed with respect to nomenclature. We have included all punctate trackways with a median groove in Protichnites, and used the oldest ichnospecies name available for a specimen with a particular number and orientation of punctate imprints. Diplichnites is of uncertain morphology, lacks priority over several other 'grooveless' ichnotaxa, and has inconsistent historical usage. Although the name is entrenched in the literature, it would be difficult to provide a case for 'stability' as an all-encompassing name for 'grooveless' ichnotaxa. We choose to retain Diplichnites, but utilize the diagnostic restrictions advocated by Fillion and Pickerill (1990), which do not produce conflict with Hitchcock's $(1858,1865)$ more senior ichnotaxa. This permits numerous subsequently introduced ichnotaxa that have obscure or inconsistently adopted morphologies to be included within either Diplichnites or a Hitchoock ichnotaxon. Though the resulting stock of trackway names is considerable, it should not be found unwieldy to future workers.

\section{SYSTEMATIC ICHNOLOGY}

Trace fossils were encountered at various localities, designated TF00 to TF36, in western Cape Breton Island. Every separate toponomic occurrence of trace fossils has been given an 'assemblage' number. Hence, each different trace-fossil assemblage at a particular locality is given the same locality number but distinguished with a separate letter. Complete assemblage numbers, for example, would be 'TF03a' and 'TF03b' from locality 3. Assemblages from localities containing tracks and trackways are shown in Figure 1. Other localities preserve only burrows, trails, pits, or coprolites (see Keighley and Pickerill, 1997). Specimens, where collected, are currently housed in the collections of the Geology Department at the University of New Brunswick (U.N.B. S-255). In total, six trackway ichnogenera were identified that comprise a total of two named ichnospecies, seven ichnospecies retained in open nomenclature, and six unnamed ichnospecies. A further ten track and trackway morphologies were retained in the vernacular since they are not attributable to particular ichnotaxa. Systematic listings follow the format of Keighley and Pickerill (1997).

\section{Ichnogenus Diplichnites Dawson, 1873}

Diagnosis: Trackway consisting, in epirelief, of two similar rows of simple, striate to punctate marks oriented transverse to slightly oblique to the axis of the trackway, and lacking an intersecting longitudinal furrow. Preservation is reversed in hyporelief (modified from Fillion and Pickerill, 1990).

Type ichnospecies: Diplichnites aenigma Dawson, by original monotypy.

Nomenclatural discussion: At least four ichnospecies of Diplichnites have been named, with several other ichnospecies having, at various times, been transferred to this ichnogenus, for example: $D$. aenigma Dawson, $D$. incertipes (Matthew), D. minor (Matthew), D. triassicus (Linck), D. gouldi (Gevers et al.), D. govenderi Savage, D. cuithensis Briggs, Rolfe, and Brannan, and $D$. binatus Webby. However, several are likely junior synonyms either of each other, or of other ichnospecies currently contained within alternative ichnogenera that, following Seilacher's scheme (sensu Fillion and Pickerill, 1990), could be included within Diplichnites. Others are probably best excluded from such synonymy because they do not comply with Fillion and Pickerill's (1990) restriction.

Numerous different trackway morphologies assignable to Diplichnites (or one of its many potential junior synonyms) have been identified in the present study, but because of the problems in determining viable ichnospecific taxobases, the material described herein is left in open ichnospecific nomenclature. Affinities to particular ichnospecies are given where material is of sufficient quality and distinctiveness, though it is recognized that more senior synonyms for such ichnospecies may ultimately be found to exist. The remaining material is grouped together as 'types' of Diplichnites isp.

\section{Diplichnites cf. logananus (Marsh, 1869) [nov. comb. - isp. previously in Protichnites] Figure 3A}

Description: Three trackways are preserved as TF02d in positive hyporelief on the sole of a low angle, cross-stratified, finegrained sandstone. The trackways lack a median groove and comprise individual marks, transversely oval or crescentic in outline, and up to $2 \mathrm{~mm}$ in width. The individual marks are well spaced, and arranged either in single series or, rarely, in

Fig. 3. 3A = Diplichnites cf. logananus: three specimens (arrowed) from TF02d preserved in positive hyporelief (mag. $x$ 0.7). $3 B=$ Diplichnites isp. type A, Protichnites cf. variabilis and cf. Protichnites carbonarius, preserved as undertracks in convex hyporelief, from TF01a (mag. x 0.5). Diplichnites runs from centre to right (arrows). ?Protichnites carbonarius is shown bottom right (black arrow), and Protichnites cf. variabilis is shown top left (white arrow)-detailed in 3C (mag. $\times 1.7$ ) and 3D (mag. $\times 1.7$ ), respectively. 3E = Protichnites isp. type C and Gluckstadtella cooperi, preserved in concave epirelief, from TF02a (mag. $x$ 0.5). Where G. cooperi passes into Protichnites isp. type C (white arrow) is detailed in $3 F$ (mag. $\times 3.0$ ), and where the trackways cross (black arrow), is detailed in $3 G$ (mag. $x$ 1.7). Ethologically, the organism most likely alighted on the substrate with its posterior end facing the right of the page and then moved off towards the left. Illumination of all specimens is from the top left. 

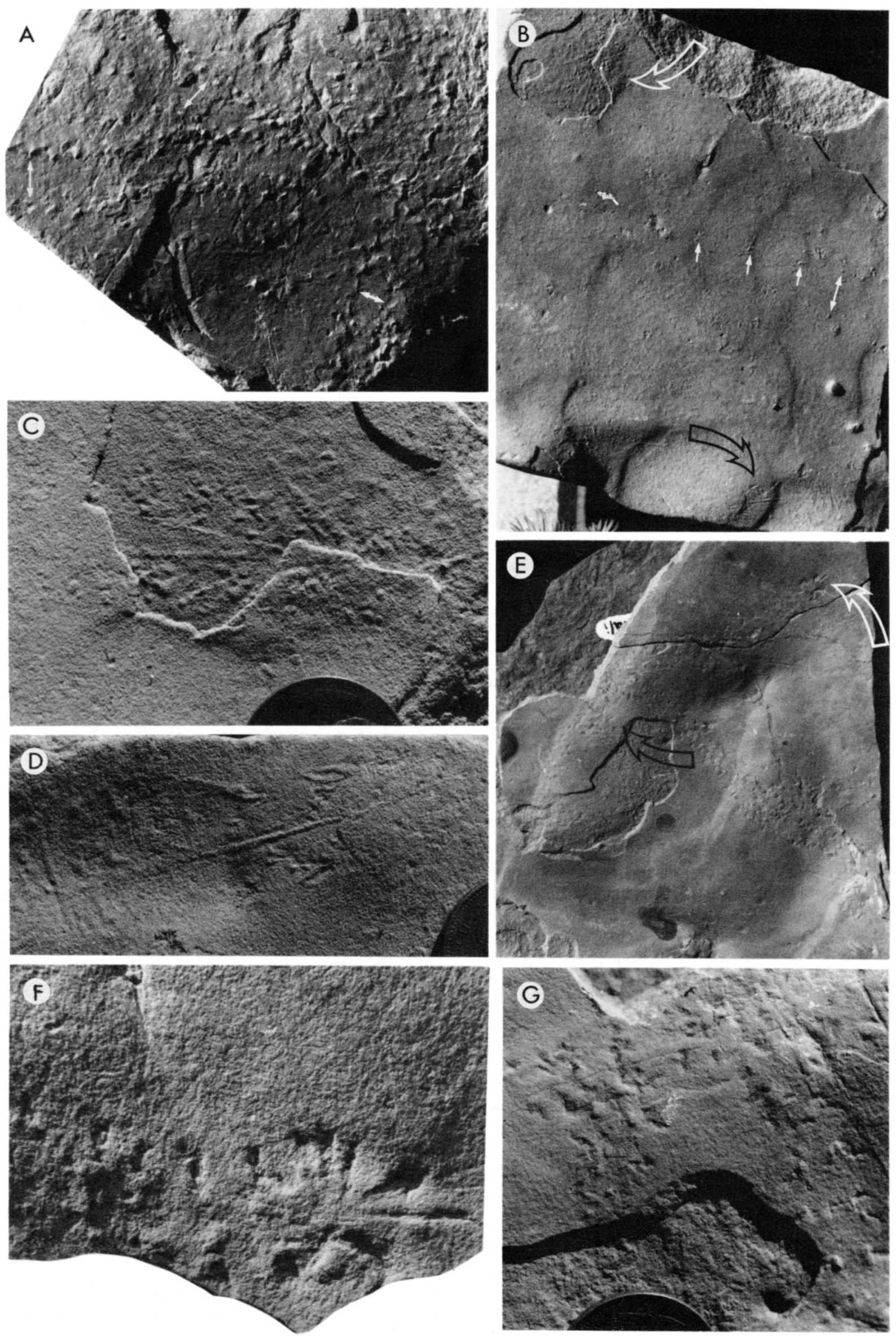
paired oblique series where natural track cycles develop en echelon. Due to poor preservation, there is no clear indication of how many imprints form a natural track cycle. Two of the trackways, one $15 \mathrm{~mm}$ wide, the other $18 \mathrm{~mm}$ wide, converge but do not cross. The other trackway is of similar width but less distinct.

Remarks: Protichnites logananus was the first name used to describe quite widely spaced punctate marks that formed single series (or rare dual series where the natural track cycle became en echelon) of imprints. The ichnogeneric assignment, as discussed earlier, is without merit but, because the morphology is distinct, the ichnospecific epithet 'logananus' remains available for that morphotype when in combination with a different ichnogeneric name (I.C.Z.N., Article 48). Following Fillion and Pickerill's (1990) use of Diplichnites, and the inapplicability of Merostomichnites and Acripes as names for such trackways, it is included as Diplichnites cf. logananus.

\section{Diplichnites isp., type A Figure 3B}

Description: Vague series of punctate impressions and inner bifid impressions preserved in convex hyporelief, likely as undertracks, on the base of a current rippled, fine-grained sandstone (TF01a). The marks are dispersed, with a 10 to 20 $\mathrm{mm}$ gap between series, and they are quite wide $(25 \mathrm{~mm})$. No median groove is preserved.

Remarks: No ichnospecific affinities could be attempted due to the poor preservation of the trackways.

\section{Diplichnites isp., type B Figure 5E}

Description: Two vague trackways preserved in convex hyporelief, crossing or crossed by one or two specimens of Protichnites cf. scoticus on the base of a fine-grained sandstone (TF20b). The better-preserved trackway (11 mm wide) crosses within a bend of (?one of) the Protichnites specimens. It preserves, in one row, three series, and in the second row two sets of small punctate prints numbering three or four and oriented nearly normal to the trackway axis.

Remarks: The transversely in-line, triple-punctate nature of the individual marks invites comparison with Etterwindichnus (=Diplichnites) regularis Walter. However, an insufficient length of trackway is preserved even for this provisional ichnospecific assignment.

\section{Ichnogenus Gluckstadtella Savage, 1971}

Modified diagnosis: Surface impression consisting of up to six pairs of radiating striae. One or two pairs are oriented parallel to the long axis of the trace at one end. Other pairs are shorter and directed away from the other pairs (modified from Savage, 1971).
Type ichnospecies: Gluckstadtella cooperi Savage, by original monotypy.

Nomenclatural discussion: Savage's (1971) original diagnosis has been modified herein to make it less interpretative. In the original diagnosis, the longer striae were considered to be the anterior appendage marks, though without explanation or evidence to the contrary (i.e., that the longer striae could be the posterior appendage marks). Though the distinctiveness of the overall shape makes recognition of the producer as an arthropod virtually without doubt, such commentary has also been removed from the diagnosis. Rotterodichnium longinum Walter also has six pairs of appendages and could be incorporated within the ichnogenus, though the considerable length of many of the striae may warrant retention of the ichnospecies name.

\section{Gluckstadtella cooperi Savage, 1971 Figure 3E, G}

Diagnosis: As for the modifed ichnogenus.

Description: The specimen is preserved in concave epirelief on a current rippled, very-fine-grained sandstone (TF02a). A median groove terminates at one end of the trace fossil, where it is more deeply impressed, but at the opposite end it is continuous into the trackway Protichnites isp., type C. Six striae radiate out on each side of the median groove. Those arranged anticlockwise from the terminal end of the median groove are the best preserved. They consist of a pair of almost longitudinally oriented striae, a group of three striae arranged more or less transversely, and a single stria arranged obliquely to longitudinally at the transition of the trace into the adjacent trackway. The same pattern is less well distinguished in a clockwise direction on the other side of the median groove.

Remarks: Apart from the original diagnostic work and a comparison of material with this ichnospecies by Dias-Fabricio and Guerra-Sommer (1989), no other specimens have been assigned to this ichnotaxon. In our material the trace fossil forms, with the trackway of Protichnites isp. type C, a compound specimen. It is considered to mark the commencement of the trackway, the organism having settled on the substrate at this location before moving away. This interpretation is supported by the presence of the deeply impressed median groove, likely a telson drag mark, that continues through the length of the trace and was likely produced as the organism moved away (Fig. 3E). The termination of the median groove was where the organism first rested its telson on the substrate and must be considered posterior (Fig. 3G). Accordingly, the most obliquely oriented and paired striae probably represent the hindmost appendages, contra Savage (1971).

\section{Ichnogenus Hexapodichnus Hitchcock, 1858}

Diagnosis: Trackway comprising two similar rows of marks lacking a median groove (or ridge in hyporelief). Natural track 
cycle of three striate imprints, inner imprints oriented longitudinally, outer imprints parallel to each other or outwardly divergent and oriented obliquely to the axis of the trackway (after Hitchcock, 1858).

Type ichnospecies: Hexapodichnus magnus Hitchcock, by subsequent designation (Lull, 1953).

Nomenclatural discussion: By following Fillion and Pickerill's (1990) criteria for assignment of material within Diplichnites, this ichnotaxon must be excluded from such synonymy. This is because, as with several other 'six-footed' ichnogenera introduced by Hitchoock (1858), at least one of the imprints in the natural track cycle is oriented longitudinally. Herein, we have followed Hitchcock $(1858,1865)$ and not considered Hexapodichnus as synonymous with the other 'six-footed' ichnogenera, Copezia or Grammepus; however, a final decision should be left to a more complete review of trackway ichnotaxa. Two ichnospecies of Hexapodichnus were originally described, $H$. magnus Hitchoock, and $H$. horrens Hitchcock. Whereas in Hitchcock's (1858) ichnogeneric diagnosis the track series was stated to have alternate symmetry, herein such a comment has been excluded because, whereas such symmetry is true for most of the type trackway of $H$. horrens, locally there is staggered or opposite symmetry (sensu Trewin, 1994).

\section{Hexapodichnus horrens Hitchcock, 1858 Figure 4A-C}

Description: As many as eight trackways are present, forming suites TF36a and TF36b. Almost all are preserved in concave epirelief on a $15 \mathrm{~mm}$ thick, parallel (subhorizontal) laminated, very-fine-grained sandstone. The one (or two) trackway forming TF36b is preserved in convex hyporelief and counterpoint concave epirelief.

Although it can be determined that a maximum of three imprints occur in a natural track cycle, preservation is highly variable even within one trackway. The imprints range from three distinct and offset tapering marks, to three intergrading marks that could be mistaken for separate oblique striae (Fig. $4 C)$, to a mixture of striate to punctate marks per natural track cycle (Fig. 4B). Individual prints are best observed at turns in the trackways; straighter sections usually result in individual prints being overprinted and a near-continuous but highly irregular tramline is present. It is at some of the turns that the trackway most resembles $H$. horrens. Here, the natural track cycle consists of a distinct grouping of one inner, longitudinally oriented stria and two outer, transversely to obliquely oriented striae, subparallel to each other (Fig. 4C). All the specimens, however, are of comparable width (10-18 mm) and the trackways may cross each other at any angle. Indeed, the apparent number of six trackways may, in reality, have been part of one long, self-crossing trackway, the connecting parts not having been preserved.
Remarks: The trackways that comprise TF36a illustrate, more than any other in the collection, the difficulties in assigning names to invertebrate trackways. The amount of variation in the detail of the imprints in any single trackway is shown to be considerable and particularly notable between straight and curved parts of the trackways (Fig. 4B, C). Herein, we have named the trackways after the best preserved morphology, namely $H$. horrens, as shown in Figure 4C. However, it should be noted that a straighter trackway (Fig. 4A) is comparable to Diplichnites gouldi. Other relatively straight sections have not been quite so much worn down to a tramline form and are more comparable to Trachomatichnus numerosus Miller. Where transverse sets of three are more visible, the material is comparable to several of the ichnospecies still included in 'Heterotripodichnus' and awaiting revision. Taking the trackways as a whole, in the sense that they become slightly wider, and individual punctate imprints become more distinct at specific turns, the material is also comparable in part to Diplichnites cuithensis described by Briggs et al. (1984). However, the trackways from TF36 are much smaller than $D$. cuithensis, considerably fewer sets of appendages were involved in producing them and, accordingly, there is usually greater spacing between individual prints at the turns. These multiple forms, each with a potentially different ichnogeneric name, emphasize the need for future rationalization of trackways or the more extensive use of compound ichnotaxa (sensu Pickerill, 1994).

\section{Ichnogenus Monomorphichnus Crimes, 1970}

Diagnosis: In concave epirelief or convex hyporelief, a series of straight to slightly wavy, parallel to intersecting striae. Groups or sets of striae may be repeated in series, or obliquely, or parallel to each other (after Fillion and Pickerill, 1990).

Type ichnospecies: Monomorphichnus bilinearis Crimes, by original monotypy.

Nomenclatural discussion: Monomorphichnus was originally established to encompass traces '...produced by a number of clawed limbs...' that were interpreted as having raked the sediment surface while the animal was being carried by a current (Crimes, 1970, p. 57). A total of eight ichnospecies have now been proposed. As well as the type, that is distinguished as having paired, parallel striae within a set, $M$. multilineatus Alpert has unpaired striae, the more central of the five or six striae being deeper and thicker than the marginal forms; $M$. lineatus Crimes et al. has diagnostic striae that are in unpaired sets; $M$. cretace $a$ Badve and Ghare has only been recognized based on its geological range; $M$. gaopoensis Yang and Yin and $M$. fusiforemis Shah and Sudan are of unknown form; $M$. pectenensis Legg has two scales of striae in the form of two thicker ridges and intervening fine striae of variable number, and $M$. intersectus Fillion and Pickerill has intersecting marks. M. cretacea has 

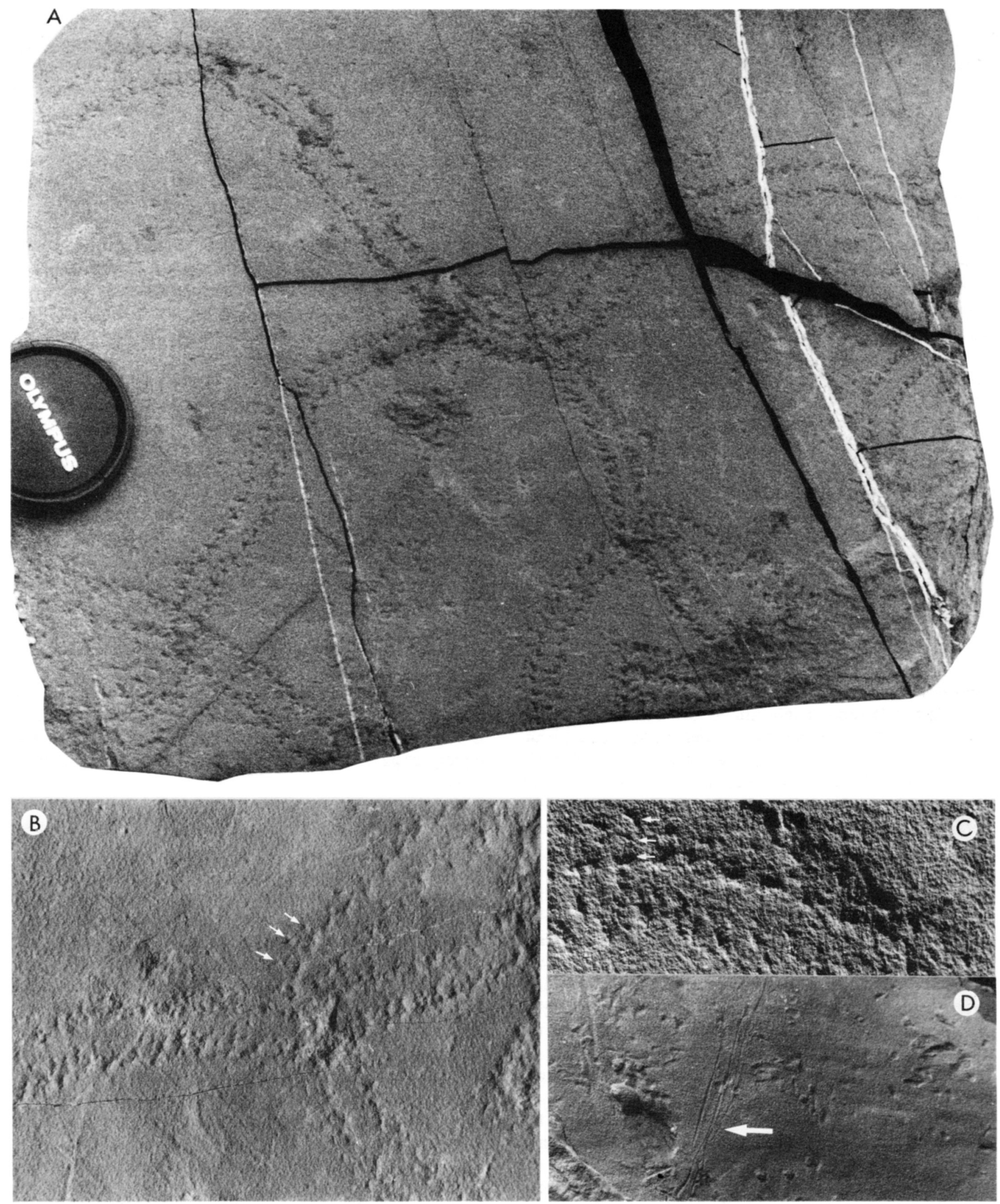

Fig. 4. 4A = Hexapodichnus horrens: several specimens preserved in concave epirelief from TF36a (mag. $x$ 0.6). 4B = Detail of 4A. On the outside of the curving trackway the outer set of punctate tracks (arrows) becomes more distinct and separated from the other imprints (mag. $x 1.1$ ). $4 \mathrm{C}=$ This detail of $4 \mathrm{~A}$ is where the trackway imprints are most distinct (arrowed) and where the characteristic morphology of $H$. horrens is best developed (mag. x 1.9). $4 \mathrm{D}=$ Monomorphichnus cf. lineatus (arrowed) and Appendage Marks, type $\mathrm{B}$, preserved as concave epichnia, from TF16b/i (mag. $x$ 0.9). Some of the appendage marks show convex-up puckering. Illumination of all specimens is from the top left. 
no valid morphological criteria for its distinction and is best considered a junior synonym of $M$. lineatus (Stanley and Pickerill, 1998).

\section{Monomorphichnus cf. lineatus Crimes et al., 1977 Figure 4D}

Description: On the top surface of a wedge-shaped, fine-grained sandstone (TF16b), is found a group of three, mostly parallel but slightly wavy, grooves. Where parallel, the individual grooves are $30 \mathrm{~mm}$ long, $<1 \mathrm{~mm}$ wide, and up to $3 \mathrm{~mm}$ apart. Toward one end of the structure, one of the outer grooves converges and then diverges from the central groove. At the equivalent position on the other side of the median groove, the third groove disappears.

Remarks: Without recurrent sets running parallel or oblique to this one, doubt remains as to whether this is a true trace fossil or simply a small, current-induced drag mark of some sort. The individual striae are unusually long, but the lack of other current indicators (e.g., tool marks) and the presence of other trace fossils on this surface suggest that the marks are biogenic in origin. Ichnospecific assignment is conditional because only one set of striae, which are not demonstrably characteristic even of $M$. lineatus, is present.

Crimes (1970) noted that a trilobite arthropod using one set of its appendages could be the producer of Monomorphichnus. Although a trilobite is unlikely to have formed this trace fossil, the strata being nonmarine, an arthropod is definitely favoured: the other trace fossils on this surface are appendage marks, presumably of invertebrate, arthropod origin, and an arthropod 'resting' trace. However, the possibility that a swimming vertebrate produced the trace cannot be entirely excluded.

\section{Ichnogenus Protichnites Owen, 1852}

Diagnosis: Trackways that, in epirelief, consist of any number of simple, punctate or short striate imprints in similar series on either side of a central, intermittent or permanent, groove or grooves (modified from Owen, 1852; Seilacher, 1955).

Type ichnospecies: Protichnites septemnotatus Owen, by subsequent designation (Häntzschel, 1962).

Nomenclatural discussion: Herein, use of Protichnites follows the proposal by Seilacher (1955). Because of the problems in determining viable ichnospecific taxobases for trackways, the material described herein is left in open ichnospecific nomenclature. Affinities to likely ichnospecies are given where material is of sufficient quality and distinctiveness, though it is recognized that more senior synonyms for such ichnospecies may ultimately be found to exist, depending upon what ichnospecific taxobases are employed in future detailed systematic study. Remaining material, though of disparate form, is grouped simply as 'Protichnites isp.' of various types.

The six ichnospecies introduced by Owen (1852) were based on slight variations in the maximum number of prod marks ('feet') per sublinear 'series', and the angle that each series subtended with the central ridge(s) and, or, groove(s). However, the type ichnospecies, $P$. septemnotatus, did not have the same number of prod marks in each repetitive 'natural track series', rarely totalling, for instance, eight (characteristic of $P$. octonotatus) instead of seven. In the terminology used herein, the number of imprints per oblique series repeat in a three, two, and two (or three) sequence. Accordingly, Owen's (1852) ichnospecific diagnosis of the type should be more liberally interpreted and possibly include $P$. alternans and $P$. octonotatus, though the latter typically has an intermittent central line. In contrast, $P$. multinotatus Owen is characterized by more densely packed imprints, and in $P$. lineatus the imprints are so dense that they commonly merge to form up to four ridges or grooves on one side of the median ridge or groove (on the other side up to five imprints form distinct punctate sets).

No ichnogeneric diagnosis was provided by Owen (1852), but a perusal of his illustrations certainly indicates that he did not restrict the number of marks per natural set in the ichnogenus, and transverse sets could have between two and five imprints. In P. scoticus, the pattern of imprints is similar to $P$. septemnotatus, but in the former a natural track cycle of six imprints is recognizable along with repetitive transverse sets of three imprints. P. carbonarius can be considered a distinct ichnospecies in that it contains alternating quadripunctate sets, arranged in a rhomboidal pattern, about a central groove. P. logananus is considered to be synonymous with Diplichnites. P. gallowayi Sharpe, has well spaced, inline, and obliquely oriented pits about a central groove.

\section{Protichnites cf. carbonarius Dawson, 1873 Figures 3C, 5A-C}

Description: The five specimens form part of TF 16a, and are preserved in convex epirelief on a wafer-thin, micaceous, veryfine-grained sandstone (Fig. 5A). Tracks vary between 12 and $15 \mathrm{~mm}$ in width. The 'median' groove, which is most frequently displaced toward, or overprints, one set of the imprints, is essentially continuous and $<1 \mathrm{~mm}$ diameter. The imprints are typically of shallow ovate shape (or rarely of short, blunt striae), arranged in rhomboidal sets repeated every 7 to $9 \mathrm{~mm}$ along the trackway. One specimen, illuminated oblique to the trackway direction (Fig. 5B) shows this arrangement. However, if this trackway is illuminated from the opposite direction, some prints merge to form a single impression, $4 \mathrm{~mm}$ long by $2 \mathrm{~mm}$ wide, that resembles a bird's foot (Fig. 5C). The specimen from TF0 1a is poorly preserved in cleavage hyporelief on a current rippled, fine-grained sandstone (Fig. 3C). Two series, comprising sets of rhomboidally clustered, semipunctate marks, are parallel about an off-centre ridge. Maximum track width is $13.5 \mathrm{~mm}$.

Remarks: The figured drawing of the original specimen (Dawson, 1873 , p. 23, fig. 1) illustrates the imprints surrounding the central groove as separate punctate to striate marks. The holotype has not been examined, but with different illumination the same 'bird's foot' impression noted in TF16a might be revealed. Miller and Knox (1985, p. 78, pl. 1G) have illustrated similar material, but, noting that the rhomboidal arrangement 

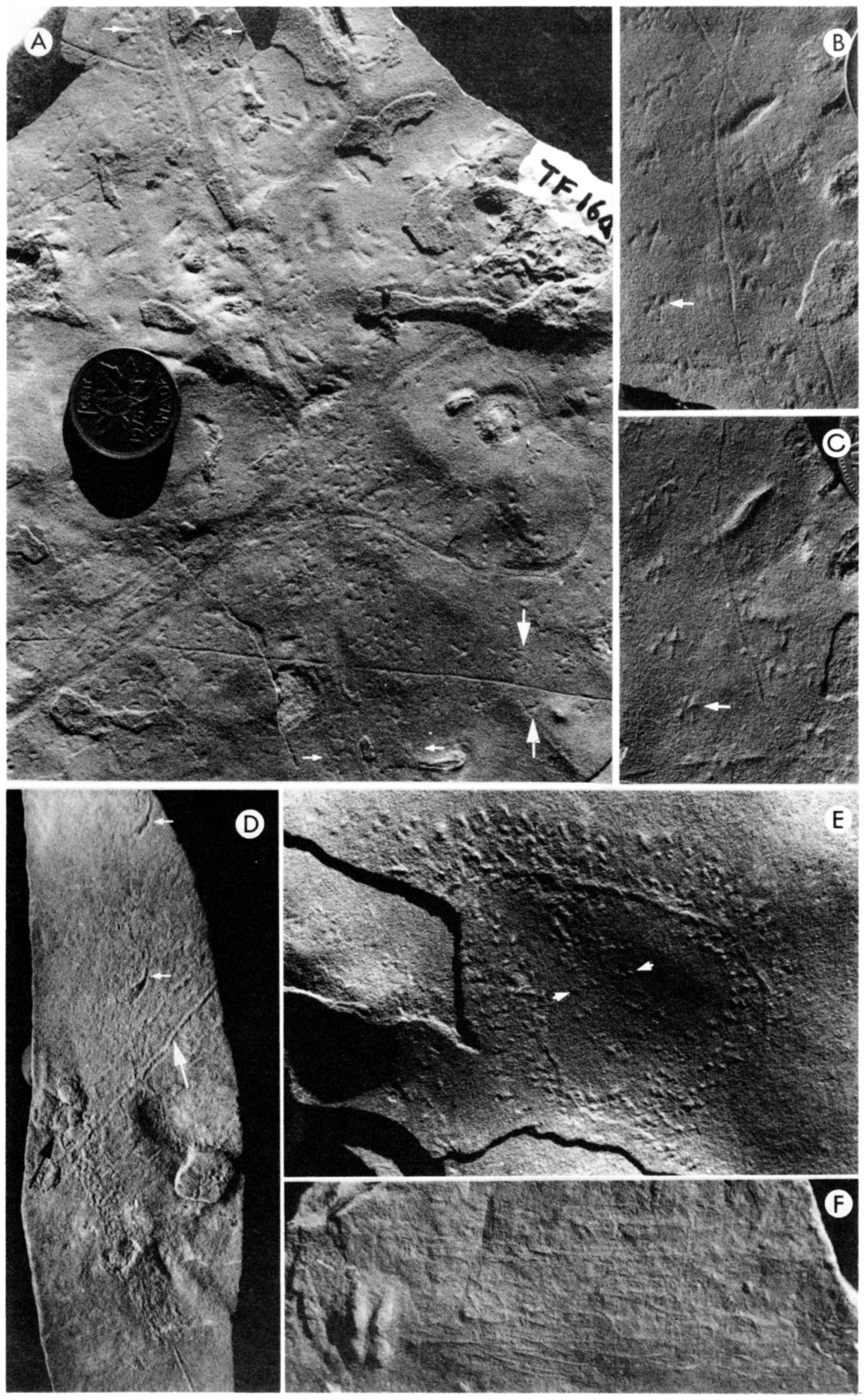
of pits enclosed an occasional bifid impression, assigned the specimen to Kouphichnium. Part of one series in the trackway assigned to Stiaria quadripedia Smith similarly displays four punctate imprints arranged in a rhomboidal manner. However, the sets in $S$. quadripedia grade into a form where the four imprints per set are arranged in a straight line (Walker, 1985, p. 291, fig. 5) and could not have been formed by a single, quadrifid appendage. Like Walker's material, the apparent single quadrifid appendage of the present specimens seems to be merely a taphonomic merging of four separate imprints.

\section{Protichnites cf. kennediea (Smith, 1909) [nov. comb.- isp. previously in Danstairia] Figure 5D}

Description: This specimen forms part of a compound trace fossil with Selenichnites (TF01a). The compound trace is preserved in convex hyporelief on a thin, rippled, fine-grained sandstone. At one end, the $50 \mathrm{~mm}$ long trackway extends for a further $10 \mathrm{~mm}$ exclusively as a central ridge. At this end of the trackway the diffuse punctate marks gradually widen toward the middle of the trackway as the central ridge disappears. The maximum width of $9 \mathrm{~mm}$ is achieved $10 \mathrm{~mm}$ from this end of the trackway and a similar width is then maintained to the termination of the trackway where it abruptly becomes Selenichnites.

Remarks: This material closely resembles some specimens of Danstairia kennediea Smith, although the ichnogenus was introduced for dissimilar material (Walker, 1985). Pollard and Walker (1984) and Walker (1985) therefore included $D$. intermedia Smith, D. unispina Smith, and D. kennediea within Stiaria intermedia. As previously noted, Stiaria itself can be included within Protichnites, and from the illustrations by Smith (1909) and Walker (1985), D. intermedia can probably be included within $P$. scoticus. $D$. kennediea has very densely packed imprints on either side of the central groove, and is also synonymous with Protichnites. Accordingly, we have provisionally included the material as $P$. kennediea, though the orthography of this ichnospecies has never been elucidated: it may be a feminized surname in the genitive, in which case it should be given the termination -ae, not -ea (I.C.Z.N., Article 31a). Irrespective, for most of the length of the trackway, the central ridge is not present; the material also resembles Trachomatichnus numerosus that, in lacking a central groove, can be considered synonymous with Diplichnites.
As well as the specimen figured by Smith (1909) and Walker (1985), similar trackways were described and illustrated by Brady (1947) under the name Isopodichnus filiciformis Brady (= Oniscoidichnus filiciformis by Brady, 1949) and by Hardy (1970, unpaginated, pl. 40) as Kouphichnium rossendalensis who attributed his compound specimens to a Xiphosurid producer.

A confident ethological interpretation can be presented because of the compound nature of our specimen, although two possible scenarios can be advanced. In the first, the groove and gradually widening series of imprints indicate the initial 'landing' of an arthropod. The organism then moved along the substrate for a distance before stopping, possibly concealing itself for a period of time and then returning to the water column. The 'launch' is thus marked by the anteriorly divergent lobes of Selenichnites. A similar interpretation was placed on some compound Protichnites-Rusophycus trace fossils by Birkenmajer and Bruton (1971). The alternative scenario reverses the direction of progress: the Selenichnites trace marks an initial settlement and possible concealment trace. The animal then moved off, and gradually became waterborne, the telson groove being the last part of the producer in contact with the substrate.

\section{Protichnites cf. scoticus Salter [in Harkness], 1856 Figure 5E}

Description: The specimen(s) is (are) preserved in convex hyporelief on the undulating base of a ?wave rippled, micaceous, fine-grained sandstone (TF20B). Where the $15 \mathrm{~mm}$ wide trackway, consisting of punctate imprints and a distinct 'median' ridge, starts to turn, the outside imprints and ridge disappear. Though the imprints on the inside of the turn continue, it is difficult to determine whether the outer imprints are still preserved or not. A poorly preserved trackway at the edge of the preserving sandstone surface contains an intermittent and ex-centric ridge, but it is uncertain whether this is a continuation of the same trackway at the completion of the turn. It appears that three punctate marks form a set that is usually linear in shape, in some cases coalescing into a simple striate mark. Such marks are oriented obliquely or perpendicular to the median ridge.

Remarks: Although a detailed description of $P$. scoticus was provided by Salter (in Harkness, 1856), only passing reference was made to Owen's (1852) work. The only clearly differ-

Fig. 5. 5A = Protichnites cf. carbonarius (thick arrows), and Protichnites isp. type D (thin arrows), from TF 16a (mag. x 1.0). A trackway of Protichnites isp. type D (centre) forms a loop. All trackways are preserved in concave epirelief. 5B = Detail of two other specimens of Protichnites cf. carbonarius preserved in concave epirelief, also fromTF16a (mag. x 1.5). 5C = Same trackway as 5B (mag. $x$ 1.5), but with reversed illumination (from bottom right) providing a different morphological appearance to the imprints; in particular two striate imprints in B (arrowed) are shown to be one quadrifid imprint in C (arrowed). 5D = Protichnites cf. kennediea, Protichnites isp. type A, Selenichnites isp. and horn-shaped trace, preserved as convex hypichnia, from TF01a (mag. $x$ 1.0). P. cf. kennediea is the most distinct of the traces present, extending from the bottom of the photo to the centre left where it is transitional into (i.e., a compound specimen with) Selenichnites isp. (black arrow). The median groove of a poorly preserved specimen of Protichnites isp. type A (thick white arrow) crosses just below Selenichnites. Horn-shaped traces marked with a thin white arrow. 5E = Diplichnites isp. type B (arrowed), is present crossing within the loop of Protichnites cf. scoticus. Preservation is in convex hyporelief, from TF20a (mag. $x$ 1.0). $5 \mathrm{~F}=$ Stiallia cf. pilosa preserved as convex hypichnia, from TF02b (mag. $\times 1.5$ ). The trace fossil Rusophycus cf. carbonarius is present far left. Illumination of all specimens, except $5 F$, is from the top left. 
ing feature of this ichnospecies from $P$. septemnotatus therefore appears to be its much smaller size in relation to the type ichnospecies, and the recognition of a natural track cycle involving six, as opposed to seven or eight appendage marks. Though in the original illustration (Harkness, 1856, p. 243, fig. 2) a natural track cycle of six imprints can be discerned, the most clearly recognizable grouping of imprints are in the form of oblique sets of three, as is the case in TF20b. No definitive natural track cycle is recognized. Since Walker (1985) did not definitively state how many appendage marks per natural set were present in her review of similar material assigned to $P$. (Stiaria) intermedia, this ichnotaxon is potentially a junior synonym of $P$. scoticus.

Protichnites cf. variabilis (Linck, 1949) [nov. comb. -isp. previously in Kouphichnium]

Figure 3D

Description: Poorly preserved specimen, $12 \mathrm{~mm}$ wide, in cleavage hyporelief, toward the base of a current rippled, fine-grained sandstone (TF01a). Only one set of indistinct, bifurcating bifid imprints is preserved on either side of a central ridge.

Remarks: Due to the poor quality of preservation in this specimen, it cannot be confidently stated that the trackway is invertebrate in origin rather than a small digitigrade vertebrate trackway. The specimen does, however, bear some resemblance to the material figured by Jarzembowski (1989, p. 224, fig. 6) as Kouphichnium aff. variabilis, that is more definitively invertebrate in origin. As previously noted, Kouphichnium is an invalid name used for polymorphous material-though typically for material containing bifid, trifid, or quadrifid imprintshence our provisional assignment within Protichnites. Assignment is provisional also because it cannot be ascertained whether the producer of the TF0la trace truly had bifid appendages, since the pattern may be due to the fortuitous overprinting of striae from different appendages that were not bifid at all.

\section{Protichnites isp., type A Figure 5D}

Description: The specimens cross-cut and seemingly predate Protichnites cf. kennediea and Selenichnites isp. on a low angle cross-laminated, very-fine-grained sandstone (TF01a). A distinct median ridge (the specimen is preserved in convex hyporelief) seems to be central to nearly continuous marginal imprints that virtually coalesce to form tramlines. The overall width of the two specimens is 15 and $16 \mathrm{~mm}$ respectively. Individual ridges are $1 \mathrm{~mm}$ wide.

Remarks: These specimens cannot be assigned to any ichnospecies because of their poor preservation.

\section{Protichnites isp., type B (not figured)}

Description: The extensively crossing trackways of TF01b are very poorly preserved on a rippled, very-fine-grained sand- stone and were not suitable for photography. No apparent preferred path direction is noted. Preserved in concave epirelief, the central furrow in each case is the best preserved part of the trackway, the marginal punctate imprints occurring only intermittently. The width of the best preserved trackway is 13 mm

Remarks: The multiple cross-cutting nature of these poorly preserved trackways negates any accurate observation of trackway form beyond recognition of a median groove, hence no ichnospecies assignment is possible.

\section{Protichnites isp., type C Figure 3E-G}

Description: Three trackways are preserved in epirelief on a (linguoid) current rippled, very-fine-grained sandstone (TF02a). All specimens are approximately the same width $(\sim 10 \mathrm{~mm})$. One trackway is transitional with the trace fossil Gluckstadtella cooperi at one end (the other 'end' corresponds to the edge of the slab). Individual appendage marks are usually transversely oriented, striate or apostrophe-form, but occasionally triangular or punctate, with one or two marks forming oblique series on each side of an intermittent, thin, median groove. This groove becomes excentric in places where the $0.15 \mathrm{~m}$ long trackway follows a slightly curving course. The two other trackways run perpendicular to the crests of the ripples, at one point converging to follow the same path for $30 \mathrm{~mm}$ before diverging and crossing the other trackway at right angles. Both have only a sporadic, short, thin median groove present, but imprint morphologies are similar to those of the other trackway. The material is therefore all considered conichnospecific.

Remarks: Though this trackway is well preserved in relation to the other 'Protichnites isp.' material, no provisional ichnospecific assignment is made because, to our knowledge, no named ichnospecies or ichnogenus with similar morphology has been defined. The only comparable material previously illustrated are the 'Type E Tracks Fp. 8a' of Nielsen $(1949$, p. 28 , fig. 19). If better quality material were to be recovered, formal introduction of a new ichnospecies would be warranted.

\section{Protichnites isp., type D Figure 3E}

Description: In comparison with the previously described specimens of Protichnites (including P. cf. carbonarius present on the same thin sandstone), the four variably preserved, crossing, epichnial specimens in TF16a have a much thicker, slightly sinuous, shallow central furrow that itself typically contains two grooves, 1.5 to $2 \mathrm{~mm}$ apart. The total track widths are between 16 to $23 \mathrm{~mm}$, though in two specimens only one row of tracks is distinct. Imprints are punctate, with an inner set of two to four prints arranged in an oblique line, and an outer set clustered in groups of two to four (in two cases possibly indicating a bifid mark). 
Remarks: If better quality material were to be recovered, introduction of a new ichnospecies would again be warranted, since we are unaware of any similar named trackways.

\section{Ichnogenus Stiallia Smith, 1909}

Diagnosis: Trackway consisting of rows of very elongate, wispy striae oriented parallel or subparallel to each other and longitudinally to the axis of the trackway (modified from Smith, 1909; Walker, 1985).

Type ichnospecies: Stiallia pilosa Smith, by subsequent designation (Walker, 1985).

Nomenclatural discussion: Following Fillion and Pickerill (1990), we do not consider this ichnotaxon for synonymy within Diplichnites because, in the first four of the five originally introduced ichnospecies of Stiallia, the individual striate imprints are not transversely oriented.

The ichnogenus was never adequately described, and no type ichnospecies was originally indicated. The five ichnospecies introduced by Smith (1909) were all similar to each other in having long, wispy striae. In order of introduction, these striae were directed longitudinally (S. aca Smith; $S$. pilosa Smith), obliquely (S. coma Smith), obliquely with crossing longitudinal striae (S. gigantea Smith), and with overlapping, transverse striae (S. scalaris Smith). Walker (1985) subsequently included $S$. (Carrickia) berriana Smith as another ichnospecies and listed $S$. pilosa as the type. The remaining ichnospecies were considered synonymous with the type because the forms can grade into each other.

In contrast, $S$. scalaris, having transverse striae, can be considered for inclusion within Diplichnites. Of the remaining ichnospecies, $S$. coma and $S$. gigantea are similar to Acanthichnus tardigradus (non Pterichnus), though in $S$. coma the natural track cycle of three imprints is more easily distinguished. S. aca and S. pilosa distinctively have longitudinally oriented striae and more than three imprints in a natural track cycle. These features distinguish these ichnospecies, and accordingly the ichnogenus, from the current definition of Acanthichnus (Hitchcock, 1858, 1865).

\section{Stiallia cf. pilosa Smith, 1909} Figure 5F

Description: Preserved in positive relief on the sole of a finegrained sandstone (TF02b), this $19 \mathrm{~mm}$ wide trackway comprises numerous striae (likely more than six per natural track cycle) that are parallel, longitudinally oriented, discontinuous, and not clearly distinguishable into any series or separate track rows (a 'left' or 'right'). Sporadic, marginal, paired striae are present that are slightly oblique from longitudinal, and gently curving. The striae are all superimposed on a broad, rounded, very shallow ridge.

Remarks: The only information originally given about $S$. pilosa is: '...a marking probably made by an animal in swimming and touching the mud in a pretty regular manner with two whisks of hairs which it drew along pretty much in the direction it was moving...' (Smith, 1909, p. 15). In fact, up to six longitudinal striae were illustrated (Smith, 1909, p. 15, fig. 23; Walker, 1985 , p. 294, fig. 9a) as forming a natural track cycle, and successive series were easily distinguishable, as were the two rows. The material in TF02b does not show how many striae are present, nor are successive series distinguishable from one another. Accordingly, ichnospecific assignment is only provisional.

\section{Appendage Marks}

Discussion: The term 'Appendage Marks' is used descriptively for small punctate pits or more elongate striae. Such marks are considered to have only one possible way of having being formed, that is, by the impression of one or more of an animal's skeletal appendages, hence the open nomenclatural term adopted. Two distinct forms are recognized.

$$
\begin{gathered}
\text { Appendage Marks, type A } \\
\text { Figures 5A, 6A, B }
\end{gathered}
$$

Description: The specimens from TF03d (Fig. 6A) are present as concave epireliefs on a wave rippled surface of silty, veryfine-grained sandstone that has a thin coating (almost a sheen) of muddy siltstone. These appendage marks form small, subrounded pits, each less than $1 \mathrm{~mm}$ in diameter, or rarely as pits at the end of thin, apostrophe-like marks. The individual imprints typically form a semicircular pattern in groups of three, four, five, or six marks per semicircle. The widest parts of the semicircular groupings are 8 to $10 \mathrm{~mm}$ apart. Specimens forming part of TF03e (Fig. 6B) and TF16a (Fig. 5A) occur on a coarser, micaceous, fine-grained sandstone. The similarly sized, subrounded pits are here much more densely packed and may form diffuse or distinct, rounded or elongate groupings. In TF16a, the appendage marks locally become sufficiently organized to suggest the presence of biserial trackways (that could possibly be assigned to Diplichnites sensu lato).

Remarks: Where the marks are more densely packed (TF03e and TF16a), the immediate subsurface may have been repeatedly 'massaged' by the arthropod limbs in order to disturb micro-organisms for food. In contrast, on TF03d, the producers appear to have been stationary, possibly indicating a resting or concealment behaviour, or a less suitable substrate for foraging.

\section{Appendage Marks, type B Figure 6B, C}

Description: In contrast to the marks described above, these appendage marks are typically much larger (up to $12 \mathrm{~mm}$ long by $2 \mathrm{~mm}$ wide), blade-like or scimitar-like in plan view, and Vshaped in cross-section. They occur widely on a fine-grained sandstone (TF16b). No major, geometrically organized patterns can be identified from the collection of marks (i.e., they do not form regular trackways). However, occasionally paired, parallel marks are noted, and possibly a series of three longi- 

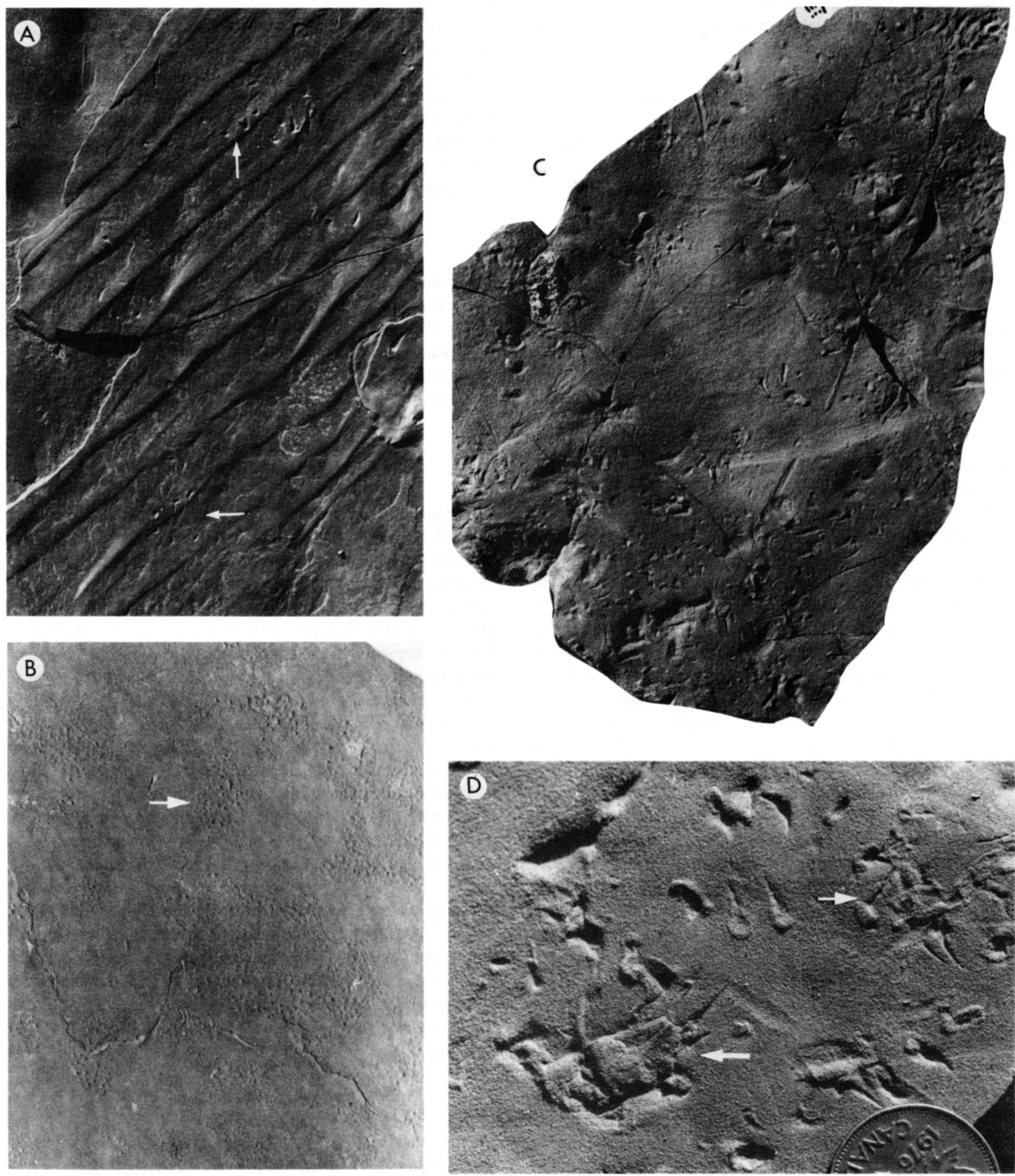

Fig. 6. $6 \mathrm{~A}=$ Appendage Marks, type $\mathrm{A}$ (large arrows), preserved as concave epichnia, from TF03d (mag. x 1.0). 6B $=$ Appendage Marks, type $\mathrm{A}$, as concave epichnia, from TF03e (mag. $x 0.7$ ). In contrast to $6 \mathrm{~A}$, the concave epichnial markings are more densely clustered and semicircular patterns are not as distinct (example arrowed). $6 \mathrm{C}=$ Appendage Marks, type $\mathrm{B}$, preserved in concave epirelief, from TF 16b (mag. $x 0.5$ ). Some markings may be part of a poorly defined trackway of which a median groove (lower left of centre to bottom right) is partly preserved. 6D = 'Arthropod Resting' Traces (arrowed) and Appendage Marks, type B, in concave epirelief, from TF $16 \mathrm{~b}$ (mag. $x 1.7$, penny coin for scale). Illumination of all specimens is from the top left. 
tudinally oriented striae form sets that recur on each side of a central groove (Fig. 6C) that might indicate a poorly preserved trackway.

Remarks: The paired, parallel marks match in size what appear to be the rearmost pair of appendage marks of the specimen described as an 'arthropod resting' trace in TF16b. The striae that occur in triplets are more problematical. They may be arthropod limb prints or, alternatively, digitigrade vertebrate prints. The very angular nature of the marks, that rarely have rucked-up margins, indicates that they are not undertracks and were likely formed on the sediment surface when it was quite firm (subaerially exposed?).

\section{'Arthropod Resting' Trace Figure 6D}

Description: The specimen occurs in concave epirelief on a vaguely current rippled, very-fine- to fine-grained sandstone (TF16b). The generally lobate mark, $13 \mathrm{~mm}$ long by $7 \mathrm{~mm}$ wide, is round at one end (interpreted as anterior) and tapers to two terminal striae at the other (posterior). External to the lobate mark and emanating striae, the preserving sandstone is slightly raised to form a rim. The lobate mark is bisected by a transverse ridge $3.5 \mathrm{~mm}$ from the anteriormost part of the trace, and a vague central ridge extends longitudinally toward the posteriormost part. Two further striae emerge from the lobate mark slightly to the anterior of the two terminal striae.

Remarks: Considerable phylogenetic interpretation encompasses the informal naming of this trace-fossil form. However, the highly distinctive shape described above means that only an arthropod could logically have produced it, since this is the only animal group that has bilateral symmetry, is segmented, and contains jointed appendages. The trace is readily interpreted as a resting or concealment imprint. In the present specimen, the transverse ridge likely marks the division of a cephalo-thorax and abdomen, the emanating striae, pairs of appendages. The abdomen of arthropods is usually larger than the cephalo-thoracic region, and since the longer striae emerge from the end of what is therefore considered to be the abdomen, the striae probably represent the hindmost appendages. The lack of adjoining trackways on the preserving medium suggests that the producer must have flown, hopped, or swam to its resting place-numerous insect groups (e.g., grasshoppers) hop using their hindmost appendages. The sharpness of the outlines to all the marks on TF16b indicates that the sediment was likely firm and subaerially exposed, favouring a hopping or flying producer.

\section{Horn-shaped Surface Traces Figure 5D}

Description: The two horn-shaped impressions are 7 and 9 $\mathrm{mm}$ long with a maximum width of $3 \mathrm{~mm}$. Both are oriented in the same direction and are approximately $35 \mathrm{~mm}$ apart adjacent to the other trace fossils forming TF0la.
Remarks: The orientation of the two horn-shaped tracks suggests that they might represent the repetition of a large appendage that produced successive imprints on one side of a large, wide trackway - the rest of the trackway not being preserved.

\section{Vertebrate Trackways}

Discussion: In light of nomenclatural confusion due to the frequent assignment of a particular 'vertebrate trace' to a particular producer (and to a particular age), and the generally poor quality of the specimens encountered in the present study, the trackways are retained in open nomenclature. However, the dimensional information that was obtained from them is summarized in Table 1.

\section{Vertebrate Trackway, type A Figure 7A, B}

Description: The specimens in TF03h are present as positive hyporeliefs on a vaguely wave rippled, fine-grained sandstone. Two of the trackways cross, and are divergent from each other at an angle of $\sim 70^{\circ}$. One of these trackways is 65 $\mathrm{mm}$ wide, but poorly preserved: there is only scant preservation of both right- and left-sided footprints. The best preserved print may indeed be part of the other trackway that crosses at this point. This other trackway is $0.2 \mathrm{~m}$ long and up to $57 \mathrm{~mm}$ wide. It contains seven right-sided footprints, of which prints R3 to R6 are best preserved, and seven leftsided footprints, though $\mathrm{L} 1$ to $\mathrm{L} 4$ and $\mathrm{L} 7$ are particularly poorly preserved (L1-L2 have been partly destroyed by the opening of a large desiccation crack, subsequently infilled by the sand that now moulds and preserves the remaining prints). Both series are in-line (i.e., they do not sprawl), and successive serial prints are approximately equidistant. Accordingly, determination of manus and pes is subjective. Stride length of all the footprints appears to be between 55 and $72 \mathrm{~mm}$, and the better-preserved footprints give pace lengths of 45 to 64 $\mathrm{mm}$, and a step angle of $76^{\circ}$ to $84^{\circ}$ (Table 1 ). Most of the distinctive prints are semidigitigrade, between 21 and $26 \mathrm{~mm}$ in length and 17 to $22 \mathrm{~mm}$ in width. R4, R6, and L5 have the 'toes' of the first three digits in-line and forming a somewhat oblique angle to the trackway axis. R5 and L6 have the first three digits offset and slightly in-turned. The fourth digits are longest and point down the trackway axis, the fifth digits being short, offset, and out-turned.

Remarks: Though two trackways are poorly preserved, all three footprint trackways have similar dimensions and morphology. Two different types of prints are present in the better-preserved trackway, indicating a quadripedal producer, although determining which prints are the manus, and which are the pes, is difficult. Both the manus and pes are likely five toed. The producer of the trackways did not sprawl, as shown by the in-line nature of each series of footprints, and was not moving efficiently, as illustrated by the low step angles. Of previously described Carboniferous vertebrate prints, those ascribed to Hylopus minor Dawson or Pseudobradypus (non 
Table 1. Vertebrate Trackway, type A

Trackway breadth: $57 \mathrm{~mm}(\max )$

Trackway length: $200 \mathrm{~mm}$

$\begin{array}{lccccccccccccc}\text { Print: } & \text { L1 } & \text { L3 } & \text { L4 } & \text { L5 } & \text { L6 } & \text { L7 } & \text { R1 } & \text { R2 } & \text { R3 } & \text { R4 } & \text { R5 } & \text { R6 } & \text { R7 } \\ \text { (impression) } & - & - & - & \text { sd } & \text { sd } & - & - & - & \text { sd } & \text { sd } & \text { sd } & \text { d(?sd) } & \text { ?pl } \\ \text { (length) } & - & - & - & 26 \mathrm{~mm} & - & - & - & - & - & 23 \mathrm{~mm} & 21 \mathrm{~mm} & - & - \\ \text { (width) } & - & - & - & 21 \mathrm{~mm} & - & - & - & - & - & 22 \mathrm{~mm} & 17 \mathrm{~mm} & - & - \\ \text { (number of digits) } & 3+ & ? 3 & ? 4 & 5 & ? 3 & ? 3 & - & - & 3+ & 3+ & 5 & 3+ & -\end{array}$

\begin{tabular}{|c|c|c|c|c|c|c|}
\hline $\begin{array}{l}\text { Stride: } \\
\text { (length) }\end{array}$ & $\begin{array}{l}\mathrm{R} 2--\mathrm{R} 4 \\
73 \mathrm{~mm}\end{array}$ & $\begin{array}{l}\mathrm{R} 3-\mathrm{-R} 5 \\
72 \mathrm{~mm}\end{array}$ & $\begin{array}{ll}\text { R4--R6 } & \text { R5--R7 } \\
65 \mathrm{~mm} & 70 \mathrm{~mm}\end{array}$ & & & \\
\hline $\begin{array}{l}\text { Pace: } \\
\text { (length) }\end{array}$ & $\begin{array}{l}\text { R4--L5 } \\
64 \mathrm{~mm}\end{array}$ & & $\begin{array}{l}\text { L5--R6 } \\
55 \mathrm{~mm}\end{array}$ & $\begin{array}{l}\text { R5--L6 } \\
59 \mathrm{~mm}\end{array}$ & & $\begin{array}{l}\text { L6--R7 } \\
45 \mathrm{~mm}\end{array}$ \\
\hline (angulation-degrees) & 1 & $68 \mathrm{deg}$. & l & 1 & $84 \mathrm{deg}$. & 1 \\
\hline
\end{tabular}

Hylopus, non Asperipes) caudifer (Dawson) bear the closest resemblance, both being five toed with manus and pes of 20 $\mathrm{mm}$ diameter, the former having a gait of $60 \mathrm{~mm}$ and stride of $80 \mathrm{~mm}$, the latter a gait of $80 \mathrm{~mm}$ and stride of $75 \mathrm{~mm}$ (Sarjeant and Mossman, 1978).

\section{Vertebrate Trackway, type B Figure 7C}

Description: These marks are preserved on the base of a rootletbearing red sandstone (TF08a), and form sets of two, three, or four, essentially straight (10-13 mm long by 2-3.5 mm wide), sausage-shaped marks in positive relief. Components in each set are parallel and oriented longitudinally to the trackway direction. Separate sets within a series appear to be widely spaced and out-of-phase with what probably is the other series.

Remarks: The trackways, being oriented longitudinally, may represent the swimming activity of a vertebrate. Similar, but much larger, sausage-shaped marks that occur in pairs as opposed to threes, have likewise been interpreted by Boyd and Loope (1984) as vertebrate swimming tracks. Alternatively, they may be the undertracks of an agile (?running) vertebrate. Most similar are Attenosaurus jonesii Aldrich and Hylopus logani (Dawson) although the latter ichnotaxon displays up to five straight, sausage-shaped marks per set (Sternberg, 1933; non Matthew, 1904, 1905).

\section{Vertebrate Trackway, type C Figure 7D}

Description: Only two left-sided and three right-sided prints are preserved hypichnially on the undulating, ?wave rippled base of a very-fine-grained sandstone (TF20a). Accordingly, the $\sim 0.09 \mathrm{~m}$ long by $\sim 0.11 \mathrm{~m}$ wide trackway is not well defined (Table 2). The R1 print has four prominent, parallel digits of approximately equal length $(8-11 \mathrm{~mm})$ extending forward from what appears to be an elliptical sole print $20 \mathrm{~mm}$ long by 15 $\mathrm{mm}$ wide. The 5th digit is outwardly (abaxially) offset from this sole but is of similar length to the other digits. The more axial R2 print is less distinct and only three parallel, forward pointing, and rather thick digits, $15 \mathrm{~mm}$ in total width, are present. R3 preserves only three elongated digits extending from a $15 \mathrm{~mm}$ wide sole. $\mathrm{L} 1$ and $\mathrm{L} 2$ are slightly smaller and only preserve three digits. Both are considered incomplete.

Fig. 7. 7A = General distribution and preservation of Vertebrate Trackways, type A, from TF03h (mag. $x$ 0.3). Two trackways, preserved in convex hyporelief, are figured extending (in the directions of movement of the producers) from top centre to lower left, and from top centre to bottom right. The latter trackway is detailed, in part, in 7B, and shows footprints L4 to L6 and R4 (arrowed in 7A) to R6. 7C = General morphology of Vertebrate Trackway, type B, from TF08a (mag. x 0.4). Trackway, comprising widely spaced sets (arrowed) of two or three, parallel, sausage-shaped markings, is preserved as convex hypichnia. $7 \mathrm{D}=$ Vertebrate Trackway, type $C$, from TF20a (mag. $x$ 0.5). The five prints making up this trackway are present as convex hypichnia on a rippled surface. Lighter coloured parts of the surface represented the upslope for the tracemaker. 7E = Vertebrate Trackway, type E, from TF29d (mag. $x$ 0.1). Obliqueangle field photograph of large vertebrate trackways preserved, uncertainly, as hypichnia. For the better preserved trackway, the producer moved from top left of centre to bottom right, and the producer's right-sided imprints are best preserved. The left-sided imprints of another, less distinctively preserved trackway, are present on the right of the photo-the producer having been moving in the opposite direction (from bottom to top). Specimen uncollectible. 7F = Vertebrate Trackway, type F, from TF32a (mag. $x$ 1.7, penny coin for scale). Trackway (likely swimming tracks) is preserved in convex hyporelief. Illumination of all specimens is from the top left. 

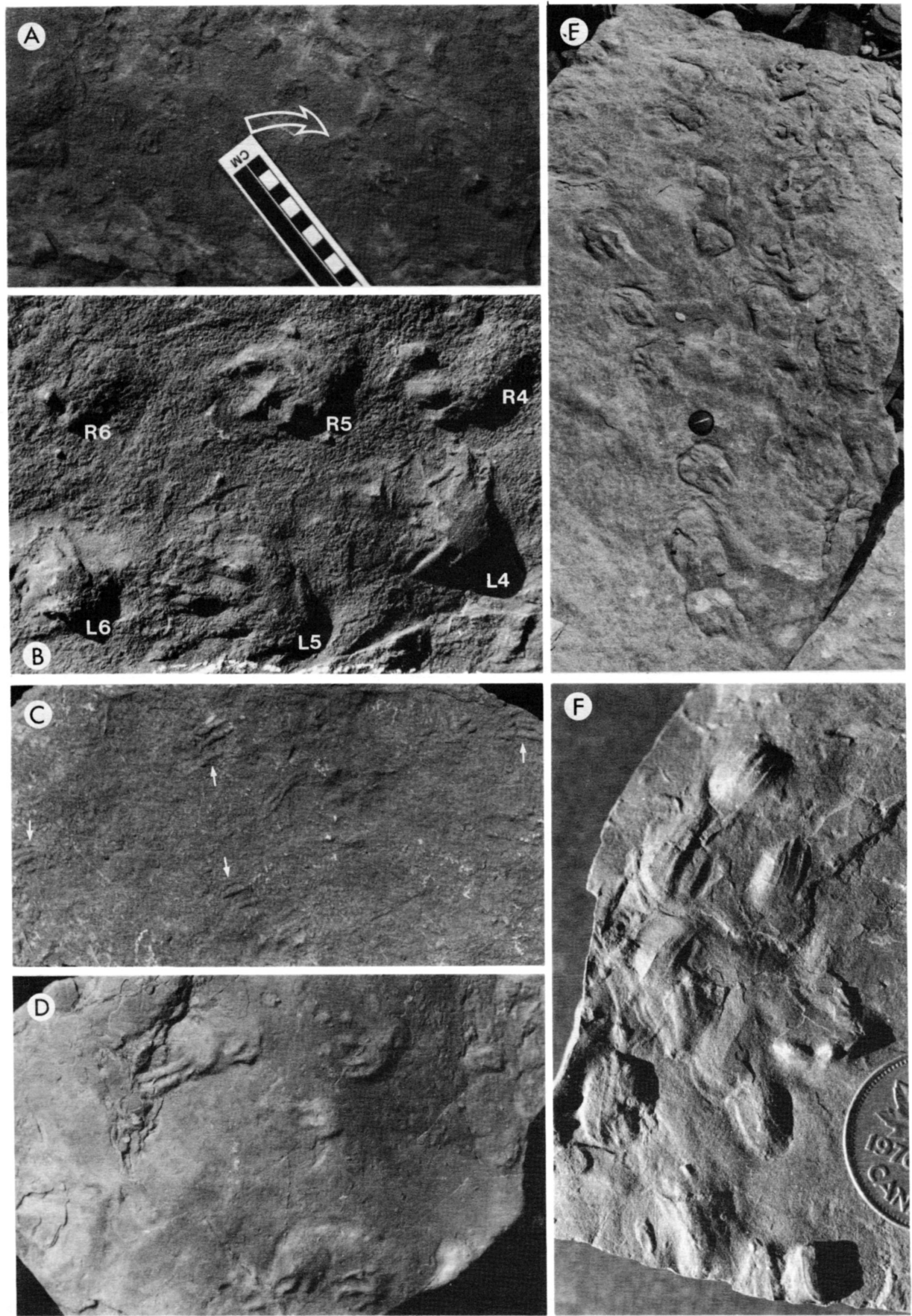
Remarks: Prints R1, L2, and R3 are considered to be the pes prints because of their larger size. On the basis of size, overall shape of the sole, and number and arrangement of digits, R1 is readily comparable to the pentadactyl hindfoot mark of Asperipes avipes Matthew. L2 and R3, however, are insufficiently well preserved to provide supporting evidence. L1 and R2, as preserved, are both tridactyl, which also corresponds to the diagnosis of $A$. avipes, though the supposedly long sole of an $A$. avipes manus was not noted. Consequently, the few complete prints in this trackway makes conclusive assignment to this ichnotaxon unwarranted.

Part of the problem for the incompleteness of each mark appears to be the undulating nature of the substrate upon which the trackmaker walked. In particular, R3 appears to indicate some slippage of the producer's foot back down the side of a ripple.

\section{Vertebrate Trackway, type D Figures 8A-C, 9A-C}

Description: A considerable variety of individual prints can again be observed as hypichnia on the bases of massive or vaguely horizontally laminated, fine- to medium-grained sandstone boulders (TF29b and TF29c-measured specimens C and $D$ of Table 3 respectively, and TF29e-measured specimens A and B of Table 3). However, two general types of print are present. The semidigitigrade prints are five toed: the innermost digit is rarely recorded but when present is usually opposed and laterally directed; the fourth digit is usually the longest; the fifth digit is narrow and pointed. The distinctly plantigrade prints are long soled, tridactyl, and usually less well preserved. Data on stride lengths for two of the more distinct trackways (C and $D$ respectively, Table 3 ) give an average stride length of $103.5 \mathrm{~mm}$, pace lengths for the pentadactyl prints averaging $77.5 \mathrm{~mm}$ and $93.5 \mathrm{~mm}$, and tridactyl pace lengths averaging $84 \mathrm{~mm}$ and $98 \mathrm{~mm}$. These more distinct trackways ( $92 \mathrm{~mm}$ broad and $100 \mathrm{~mm}$ broad respectively) also preserve a repeatedly imprinted, axial tail mark. In Specimen $B$ there is the rare indication that $\mathrm{Ll}$ and $\mathrm{L} 3$ were manus prints, since L2 seems to partly overprint, and hence postdate $\mathrm{L} 3$.

Remarks: The plantigrade marks resemble several previously defined ichnogenera. Megapezia pineoi Matthew has three relatively short blunt digits, similar to the specimens described herein, but also a fourth, offset, divergent digit (this may simply not be preserved in the Port Hood Formation material). $M$. pineoi has pentadactyl forefeet but, as illustrated in the holotype, these are divergent in a semiradial pattern, with the digits all being of similar length. Interestingly, Dawson had compared this holotype with Hylopus logani several years prior to Matthew providing the specimen with its formal name (Sarjeant and Mossman, 1978). Like Palaeosauropus Hay, Hylopus contains a longer second-last digit (i.e., digit 4 on the pes). All three ichnogenera were grouped within the ichnofamily Batrachichnidae by Haubold (1970). The specimens may alternatively be compared to Matthewichnus caudifer Kohl and Bryan, or to Ichnotherium Pohlig, that Haubold and Katzung (1978) considered to be primarily Permian footprints from pelycosaurian communities that had their evolutionary roots in the faunas of the Upper Carboniferous.

The generally low step angle, typically between $70^{\circ}$ and $85^{\circ}$, indicates a slow moving producer. This is also indicated by the low stride length with respect to trackway breadth, though the trackmaker did not sprawl. Assuming that the pentadactyl prints represent the mani, then the glenoacetabular distance (body length) of the trackmaker was in the range of 80 to $90 \mathrm{~mm}$. Digits are generally rounded at their periphery, rarely with an indication of claws, as shown by the two pentadactyl prints from TF29e (Fig. 8C). Claws would suggest a

Table 2. Vertebrate Trackway, type C

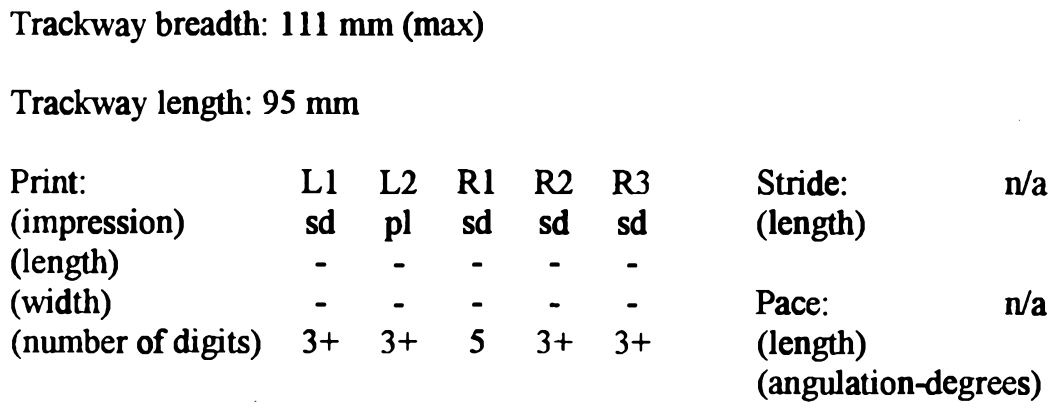

Fig. 8. 8A = Vertebrate Trackway, type D, from TF29e (mag. $x$ 0.3). The trackway (measured specimen A) is preserved in convex hyporelief. The producer moved from bottom to top. $8 \mathrm{~B}=$ Detail of area arrowed in $8 \mathrm{~A}$ (mag. $x 0.7$ ). Prints L2 and L3 (top left) are the best preserved, the sharply pointed digits possibly indicating that the producer was clawed (reptilian). $8 \mathrm{C}=$ Detail of another trackway from an unfigured portion of the same slab shown in $8 \mathrm{~A}$ (mag. $x$ 0.7). L3 (middle left) seems to be partly overprinted by L2, suggesting that L3 (and L1, lower left) was a manus print. The drag marks of the producer's tail are well preserved to the right of L2 and L3. All are field photographs with illumination from the top left. Specimens uncollectible. 

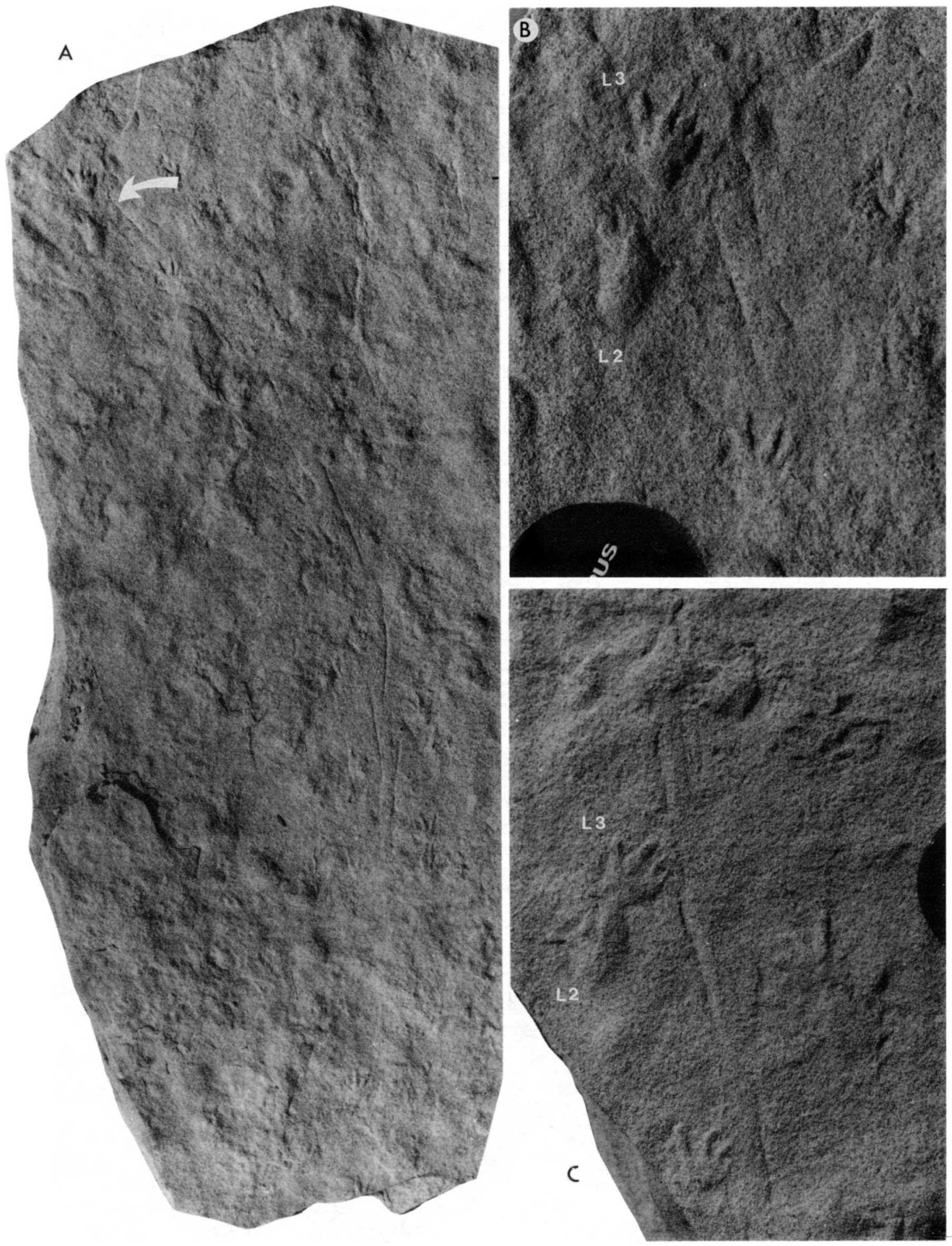

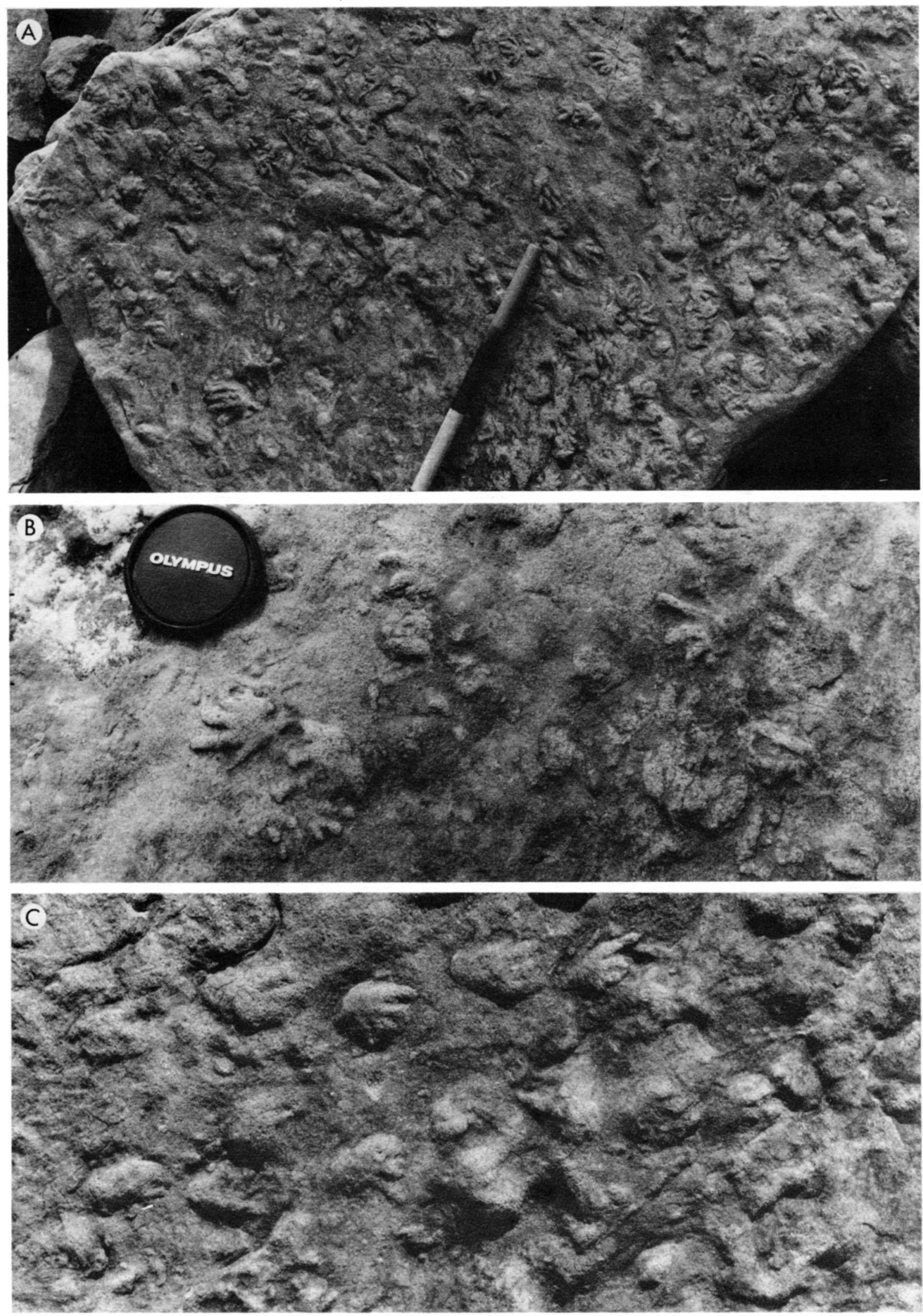
reptilian producer and, circumstantially, Baird and Carroll (1967) recovered the oldest remains of the reptile Romeriscus from beds lower within the same sequence that includes locality TF29.

\section{Vertebrate Trackway, type E Figure 7E}

Description: By far the largest vertebrate tracks belong to this type of trackway, with individual prints being up to $0.1 \mathrm{~m}$ wide by up to $0.12 \mathrm{~m}$ long. They are preserved as subdued ?hyporelief moulds on a thick (dm-scale) slab of fine- to medium-grained sandstone (TF29d). Unfortunately, preservation is not good anywhere along the $1.25 \mathrm{~m}$ length of the trackway. The right-sided prints are slightly deformed and the generally smaller, left-sided prints are virtually indistinguishable, but an approximate trackway breadth of $0.35 \mathrm{~m}$ has been measured. The other (very indistinct) tracks occur to the left of the first trackway (on the right of Fig. 7E). They appear to form the left row of a second trackway, made by a vertebrate travelling in the opposite direction.

Obtaining significant measurements from even the main trackway is difficult. It is not certain that all the prints are preserved, even on the right side (eight prints are delimited on the right side, four on the left side). If all prints are present, then the stride length is quite variable (Table 4), ranging from $0.25 \mathrm{~m}$ (L1-L3) to $0.35 \mathrm{~m}$ (R5-R7). Pace lengths, and hence step angle, cannot be ascertained with certainty, since the leftsided prints preserve too little detail to correlate a forefootbackfoot sequence with the right-sided prints.

What little detail that can be gleaned from individual prints indicates a tridactyl plantigrade form for both manus and pes prints (though which prints are the manus or pes cannot be determined). The best preserved prints (R3 and R6) contain three virtually parallel (little divarication) and rather stumpy digits, the widest part of the foot (on R6 and R8) being midway along the sole. Most of the right-sided prints are somewhat turned inward, and R7 and R8 are displaced slightly to the right of the line formed by the preceding tracks.

Remarks: The poorly preserved nature of these prints precludes any nomenclature of the trackway, though in print size, trackway width, and gait, some resemblance to Pseudobradypus ungifer (Dawson) should be noted. Similar criteria also define Chelichnus gigas Jardine (cf. McKeever and Haubold, 1996, p. 1017, fig. 4) that could be the senior synonym of Pseudobradypus and thus extend the occurrence of the ichnotaxon from the Permian back into the Carboniferous. This suggestion is contrary to McKeever and Haubold's (1996) assertion that the former name should not be expanded to include trackways from older or younger strata, because we do not consider stratigraphy as relevant in the diagnosis of an ichnotaxon (see earlier comments).

The diffuse nature of some of the margins and the grooved margins of other prints suggest that the substrate (likely a grey mudstone forming in an overbank or floodplain environment) was not firm, and likely wet, when the vertebrate trackmaker traversed this area. Wet sediment would promote collapse at the margins of prints, leading to the diffuse margins and lack of distinction between digits, together with an aureole of deformed sediment surrounding them (the ?mould of the surface of this deformed sediment is visible particularly on R3 and R4). The poor definition and slightly inward turn of the footprints suggest that the underlying sediment was submerged, with a cross-current (from right to left as viewed on Fig. 7E), though the preserving strata provide no evidence to support or refute this suggestion, being diffusely horizontally laminated sandstone.

The vertebrate itself was likely an inefficient walker, as it produced a trackway that is as broad as the animal's stride length. This would suggest an amphibian producer although, conceivably, environmental conditions (e.g., the cross-current) may have precluded large strides even if the trackmaker were reptilian.

\section{Vertebrate Trackway, type F Figure 7F}

Description: The specimens occurring as TF32a are present as a cluster of mounds (positive hyporeliefs) on the base of a silty, very-fine-grained sandstone. Up to four, narrow, approximately parallel, positive relief striae cross each of a group of four elliptical mounds, the striae being oriented more-orless parallel to the long axes of the mounds. The striae and the long axes of the mounds themselves have similar orientations and form a loose biserial trackway of four prints (left of centre, Fig. 7F). Several other low elliptical mounds, of similar dimensions but with less distinct ridges or lacking ridges (bottom left, Fig. 7F), are oriented at a slight angle to the others.

Remarks: The trace fossil is interpreted to be the trackway produced by a vertebrate swimming just above the sediment surface. The ethological interpretation of a swimmer, as opposed to a walker, is preferred because the termination (or commencement-direction of travel is not œrtain) of the trackway is in the middle of the preserved slab and the striae traverse the length of the mound. The narrow parallel striae are likely evidence of protruding claws that scoured slightly deeper into the underlying sediment as the animal 'doggy paddled' over the surface. It is the observation of two rows of marks that leads to the suggestion of a vertebrate producer, one row reflecting left-sided paddling limbs, the other row right-sided

Fig. 9. 9A = Vertebrate Trackway, type D, from TF29b (mag. x 0.2). A multitude of similar trackways are present in convex hyporelief crossing this slab. Measured specimen $C$ is present from upper centre to upper left (the direction of movement of the producer). $9 B=$ Vertebrate Trackway, type D, from the same slab illustrated in 9A (mag. $x$ 0.5). Producer moved from right to left. $9 \mathrm{C}=\mathrm{Vertebrate}$ Trackway, type D, from TF29c (mag. x 0.4). Detail of measured specimen D, that is preserved in convex hyporelief. Producer moved from left to right. All are field photographs with illumination from the top left. Specimens uncollectible. 
Table 3. Vertebrate Trackway type D

Specimen A

Trackway breadth: $84 \mathrm{~mm}$ (max)

Trackway length: $200 \mathrm{~mm}$

\begin{tabular}{|c|c|c|c|c|c|}
\hline $\begin{array}{l}\text { Print: } \\
\text { (impression) } \\
\text { (length) } \\
\text { (width) } \\
\text { (number of digits) }\end{array}$ & $\begin{array}{c}\mathrm{Ll} \\
\text { sd } \\
22 \mathrm{~mm} \\
20 \mathrm{~mm} \\
? 4\end{array}$ & $\begin{array}{l}\text { L2 } \\
\text { pl } \\
\dot{-} \\
\dot{? 3}\end{array}$ & $\begin{array}{c}\mathrm{L3} \\
\text { sd } \\
25 \mathrm{~mm} \\
18 \mathrm{~mm} \\
5\end{array}$ & $\begin{array}{c}\mathrm{Rl} \\
\mathrm{pl} \\
- \\
- \\
? 4\end{array}$ & $\begin{array}{l}\text { Stride: L1-L3 } \\
\text { (length) } 88 \mathrm{~mm}\end{array}$ \\
\hline
\end{tabular}

Specimen B

Trackway breadth: $100 \mathrm{~mm}(\max )$

Trackway length: $230 \mathrm{~mm}$

\begin{tabular}{|c|c|c|c|c|c|c|c|c|c|}
\hline $\begin{array}{l}\text { Print: } \\
\text { (impression) } \\
\text { (length) } \\
\text { (width) } \\
\text { (number of digits) }\end{array}$ & $\begin{array}{c}\mathrm{Ll} \\
\mathrm{sd} \\
22 \mathrm{~mm} \\
20 \mathrm{~mm} \\
? 4\end{array}$ & $\begin{array}{l}\text { L2 } \\
- \\
- \\
- \\
2\end{array}$ & $\begin{array}{c}\mathrm{L3} \\
\mathrm{sd} \\
25 \mathrm{~mm} \\
18 \mathrm{~mm} \\
4\end{array}$ & $\begin{array}{l}\text { R1 } \\
\text { sd } \\
- \\
- \\
4\end{array}$ & $\begin{array}{l}\text { R2 } \\
\text { ?pl } \\
- \\
? \\
?\end{array}$ & $\begin{array}{l}\text { R3 } \\
\text { ?pl } \\
? \\
?\end{array}$ & $\begin{array}{l}\text { R4 } \\
\text { sd } \\
- \\
- \\
3\end{array}$ & $\begin{array}{c}\text { R6 } \\
\text { sd } \\
- \\
- \\
23\end{array}$ & \\
\hline $\begin{array}{l}\text { Stride: } \\
\text { (length) }\end{array}$ & $\begin{array}{l}\mathrm{Ll}-\mathrm{L} 3 \\
95 \mathrm{~mm}\end{array}$ & $\begin{array}{c}\mathrm{R} 1--\mathrm{R} 3 \\
100 \mathrm{~mm}\end{array}$ & $\begin{array}{l}\mathrm{R} 2-\mathrm{R} 4 \\
95 \mathrm{~mm}\end{array}$ & $\begin{array}{l}\text { R4-R6 } \\
90 \mathrm{~mm}\end{array}$ & & & & & $\begin{array}{c}\text { mean } \\
95 \mathrm{~mm}\end{array}$ \\
\hline $\begin{array}{l}\text { Pace: } \\
\text { (length) } \\
\text { (angulation-degrees) }\end{array}$ & $\begin{array}{l}\mathrm{R} 2-\mathrm{Ll} \\
63 \mathrm{~mm} \\
\quad 1\end{array}$ & 88 deg. & $\begin{array}{l}\text { L1--R4 } \\
75 \mathrm{~mm} \\
\quad 八\end{array}$ & 86 deg. & $\begin{array}{l}\text { R4--L3 } \\
62 \mathrm{~mm} \\
\quad /\end{array}$ & 86 deg. & $\begin{array}{l}\text { L3-R6 } \\
70 \mathrm{~mm} \\
\mathrm{I}\end{array}$ & & $\begin{array}{l}\text { mean } \\
67.5 \mathrm{~mm} \\
\sim 87 \mathrm{deg} .\end{array}$ \\
\hline
\end{tabular}

Specimen C

Trackway breadth: $92 \mathrm{~mm}$ (max)

Trackway length: $365 \mathrm{~mm}$

\begin{tabular}{|c|c|c|c|c|c|c|c|c|c|c|c|c|c|}
\hline $\begin{array}{l}\text { Primt: } \\
\text { (impression) } \\
\text { (length) } \\
\text { (width) } \\
\text { (number of digits) }\end{array}$ & $\begin{array}{l}\text { Ll } \\
\text { pl } \\
- \\
\dot{-} \\
3+\end{array}$ & $\begin{array}{l}\text { L2 } \\
\text { sd } \\
- \\
- \\
2+\end{array}$ & $\begin{array}{l}\text { L3 } \\
\text { pl } \\
\dot{-} \\
\dot{3}\end{array}$ & $\begin{array}{l}\text { LA } \\
\text { sd } \\
- \\
- \\
2+\end{array}$ & $\begin{array}{l}\text { L5 } \\
\mathrm{pl} \\
\dot{-} \\
\dot{-} \\
3+\end{array}$ & $\begin{array}{l}\text { L6 } \\
\text { sd } \\
\vdots \\
\dot{3}\end{array}$ & $\begin{array}{c}\text { L7 } \\
\mathrm{pl} \\
- \\
\dot{-} \\
24\end{array}$ & $\begin{array}{l}\text { L8 } \\
\text { sd } \\
- \\
\text { is }\end{array}$ & $\begin{array}{l}\text { R2 } \\
\text { sd } \\
- \\
\dot{-} \\
75\end{array}$ & $\begin{array}{c}\mathrm{R} 3 \\
\mathrm{pl} \\
- \\
- \\
2+\end{array}$ & $\begin{array}{l}\text { R4 } \\
\text { sd } \\
- \\
\dot{-} \\
\text { is }\end{array}$ & $\begin{array}{c}\text { R6 } \\
\text { sd } \\
- \\
- \\
\end{array}$ & \\
\hline $\begin{array}{l}\text { Stride: } \\
\text { (length) }\end{array}$ & $\begin{array}{l}\mathrm{L1}-\mathrm{L3} \\
107 \mathrm{~mm}\end{array}$ & $\begin{array}{l}\mathrm{L2} 2-\mathrm{LA} \\
105 \mathrm{~mm}\end{array}$ & $\begin{array}{l}\text { L3-L5 } \\
100 \mathrm{~mm}\end{array}$ & $\begin{array}{l}\text { L4-L6 } \\
112 \mathrm{~mm}\end{array}$ & $\begin{array}{l}\mathrm{L5}-\mathrm{L7} \\
100 \mathrm{~mm}\end{array}$ & $\begin{array}{l}\mathrm{L6}-\mathrm{LP} \\
100 \mathrm{~mm}\end{array}$ & $\begin{array}{l}\mathrm{R} 2-\mathrm{R} 4 \\
102 \mathrm{~mm}\end{array}$ & $\begin{array}{l}\mathrm{R} 4-\mathrm{R} 6 \\
102 \mathrm{~mm}\end{array}$ & & & & & $\begin{array}{c}\text { mean } \\
103.5 \mathrm{~mm}\end{array}$ \\
\hline $\begin{array}{l}\text { Pace: } \\
\text { (length) } \\
\text { (angulation-degrees) }\end{array}$ & $\begin{array}{l}\text { L2-R2 } \\
82 \mathrm{~mm} \\
1\end{array}$ & $82 \mathrm{deg}$. & $\begin{array}{l}\mathrm{R} 2-\mathrm{LA} \\
70 \mathrm{~mm} \\
\quad 八\end{array}$ & $80 \mathrm{deg}$. & $\begin{array}{l}\text { L4-R4 } \\
82 \mathrm{~mm} \\
\quad 八\end{array}$ & $86 \mathrm{deg}$. & $\begin{array}{l}\text { R4-L6 } \\
75 \mathrm{~mm} \\
\text { 八 }\end{array}$ & 80 deg. & $\begin{array}{l}\text { L6-R6 } \\
84 \mathrm{~mm} \\
ハ\end{array}$ & $80 \mathrm{deg}$. & $\begin{array}{l}\text { R6-L8 } \\
72 \mathrm{~mm} \\
/\end{array}$ & & $\begin{array}{l}\text { mean } \\
77.5 \mathrm{~mm} \\
82 \mathrm{deg}\end{array}$ \\
\hline $\begin{array}{l}\text { Pace: } \\
\text { (length) } \\
\text { (angulation-degrees) }\end{array}$ & $\begin{array}{c}\text { L3-R3 } \\
88 \mathrm{~mm} \\
1\end{array}$ & $73 \mathrm{deg}$. & $\begin{array}{l}\text { R3--LS } \\
80 \mathrm{~mm} \\
/\end{array}$ & & & & & & & & & & $\begin{array}{l}\text { mean } \\
84 \mathrm{~mm}\end{array}$ \\
\hline $\begin{array}{l}\text { Glenoacetabular } \\
\text { distance: }\end{array}$ & $\mathbf{M i}$ & nt of 1 & $\begin{array}{l}-\mathrm{R} 3 \mathrm{to} \mathrm{mi} \\
91 \mathrm{~mm}\end{array}$ & soint. & $-L 6$ & & at 0 & $\begin{array}{l}-\mathrm{LS} \text { to m } \\
91 \mathrm{~mm}\end{array}$ & poin & L6-R6 & & & $\begin{array}{l}\text { mean } \\
91 \mathrm{~mm}\end{array}$ \\
\hline
\end{tabular}

Specimen D

Trackway breadth: $100 \mathrm{~mm}$ (max)

Trackway length: $265 \mathrm{~mm}$

\begin{tabular}{|c|c|c|c|c|c|c|c|c|c|c|c|}
\hline $\begin{array}{l}\text { Print: } \\
\text { (impression) } \\
\text { (length) } \\
\text { (width) } \\
\text { (number of digits) }\end{array}$ & $\begin{array}{c}\mathrm{Ll} \\
\mathrm{pl} \\
38 \mathrm{~mm} \\
22 \mathrm{~mm} \\
73\end{array}$ & $\begin{array}{c}\mathrm{L} 2 \\
\mathrm{pl} \\
45 \mathrm{~mm} \\
28 \mathrm{~mm} \\
3\end{array}$ & $\begin{array}{c}\mathrm{L3} \\
\mathrm{pl} \\
37 \mathrm{~mm} \\
32 \mathrm{~mm} \\
75\end{array}$ & $\begin{array}{c}\text { LA } \\
\text { sd } \\
42 \mathrm{~mm} \\
22 \mathrm{~mm} \\
3\end{array}$ & $\begin{array}{c}\text { L5 } \\
\text { pl/sd } \\
38 \mathrm{~mm} \\
22 \mathrm{~mm} \\
75\end{array}$ & $\begin{array}{c}\mathrm{R} 1 \\
\mathrm{pl} \\
42 \mathrm{~mm} \\
25 \mathrm{~mm} \\
3\end{array}$ & $\begin{array}{c}\mathrm{R} 2 \\
\mathrm{pl} \\
33 \mathrm{~mm} \\
-\overline{73}\end{array}$ & $\begin{array}{c}\mathrm{R} 3 \\
\mathrm{pl} \\
38 \mathrm{~mm} \\
22 \mathrm{~mm} \\
74\end{array}$ & $\begin{array}{c}\text { R6 } \\
- \\
- \\
- \\
3\end{array}$ & $\begin{array}{l}\text { R7 } \\
: \\
- \\
\vdots\end{array}$ & \\
\hline $\begin{array}{l}\text { Stride: } \\
\text { (length) }\end{array}$ & $\begin{array}{c}\mathrm{Ll}-\mathrm{L3} \\
102 \mathrm{~mm}\end{array}$ & $\begin{array}{l}\mathrm{L2}-\mathrm{LA} \\
110 \mathrm{~mm}\end{array}$ & $\begin{array}{l}\text { L3-L5 } \\
115 \mathrm{~mm}\end{array}$ & $\begin{array}{l}\mathrm{R} 1-\mathrm{R} 3 \\
112 \mathrm{~mm}\end{array}$ & & & & & & & $\begin{array}{c}\text { mean } \\
103.5 \mathrm{~mm}\end{array}$ \\
\hline $\begin{array}{l}\text { Pace: } \\
\text { (length) } \\
\text { (angulation-degrees) }\end{array}$ & $\begin{array}{c}\mathrm{L1}-\mathrm{R} 2 \\
85 \mathrm{~mm} \\
1\end{array}$ & 78 deg. & $\begin{array}{c}\mathrm{R} 2-\mathrm{L} 3 \\
102 \mathrm{~mm} \\
/\end{array}$ & & & & & & & & $\begin{array}{c}\text { mean } \\
93.5 \mathrm{~mm}\end{array}$ \\
\hline $\begin{array}{l}\text { Pace: } \\
\text { (length) } \\
\text { (angulation-degrees) }\end{array}$ & $\begin{array}{c}\mathrm{R} 1-\mathrm{L} 2 \\
100 \mathrm{~mm} \\
\quad\end{array}$ & $70 \mathrm{deg}$. & $\begin{array}{c}\mathrm{L2}-\mathrm{R} 3 \\
92 \mathrm{~mm} \\
\Lambda\end{array}$ & $68 \mathrm{deg}$. & $\begin{array}{c}\text { R3-LA } \\
103 \mathrm{~mm} \\
/\end{array}$ & & & & & & $\begin{array}{c}\text { mean } \\
98.3 \mathrm{~mm} \\
69 \mathrm{deg} .\end{array}$ \\
\hline
\end{tabular}


Table 4. Vertebrate Trackway type E

Trackway breadth: $355 \mathrm{~mm}(\max )$

Trackway length: $1.35 \mathrm{~m}$

\begin{tabular}{|c|c|c|c|c|c|c|c|c|c|c|}
\hline $\begin{array}{l}\text { Print: } \\
\text { (impression) } \\
\text { (length) } \\
\text { (width) } \\
\text { (number of digits) }\end{array}$ & $\begin{array}{l}\mathrm{Ll} \\
\mathrm{pl} \\
- \\
- \\
-\end{array}$ & $\begin{array}{l}\text { L2 } \\
\text { pl } \\
- \\
- \\
-\end{array}$ & $\begin{array}{c}\text { L3 } \\
\text { pl } \\
- \\
- \\
-\end{array}$ & $\begin{array}{c}\text { L4 } \\
\text { pl } \\
- \\
- \\
-\end{array}$ & $\begin{array}{c}\mathrm{R} 3 \\
\mathrm{pl} \\
110 \mathrm{~mm} \\
85 \mathrm{~mm} \\
3\end{array}$ & $\begin{array}{c}\mathrm{R} 4 \\
\mathrm{pl} \\
100 \mathrm{~mm} \\
- \\
-\end{array}$ & $\begin{array}{c}\mathrm{R} 6 \\
\mathrm{pl} \\
110 \mathrm{~mm} \\
95 \mathrm{~mm} \\
3\end{array}$ & $\begin{array}{c}\mathrm{R} 7 \\
\mathrm{pl} \\
112 \mathrm{~mm} \\
- \\
-\end{array}$ & $\begin{array}{c}\mathrm{R} 8 \\
\mathrm{pl} \\
110 \mathrm{~mm} \\
88 \mathrm{~mm} \\
? 3\end{array}$ & \\
\hline $\begin{array}{l}\text { Stride: } \\
\text { (length) }\end{array}$ & $\begin{array}{l}\text { R4--R6 } \\
345 \text { mm }\end{array}$ & $\begin{array}{l}\text { R6--R8 } \\
280 \mathrm{~mm}\end{array}$ & & & & & & & & $\begin{array}{c}\text { mean } \\
312.5 \mathrm{~mm}\end{array}$ \\
\hline
\end{tabular}

paddling limbs. If two series had not been observed, then assignment would have been with Monomorphichnus, which is essentially identical except for the lack of a second series of marks. Except for the presence of striae on mounds, comparison with Acanthichnus would also be warranted.

\section{Conclusions}

The trace fossils described herein are from fluvial, lacustrine, and floodplain strata comprising the Mabou and Cumberland groups. Coupled with the burrows, pits, trails, and coprolites described from the same strata by Keighley and Pickerill (1997), they represent a relatively diverse Carboniferous nonmarine ichnofauna, the surface markings alone probably having been produced by insects, reptiles, and amphibians. They also add to the diversity of trackway ichnotaxa collected from Carboniferous strata elsewhere in the Maritimes (Table 5). Collectively, the Mabou and Cumberland Group trace fossils are indicative of components of the Scoyenia ichnofacies of Seilacher (1967) and Mermia ichnofacies of Buatois and Mángano (1993), both of which, because of definitions inconsistent with the original ichnofacies concept (Seilacher, 1963, 1964), await revision-which we shall present in a future contribution.

\section{ACKNowledgements}

The Journal-appointed referees, W. Sarjeant and D. Mossman, are thanked for their detailed reviews and many constructive comments that have improved the manuscript. B. Broster, C. Laury, R. Metz, A. Park, and P. Stringer also commented significantly upon earlier drafts. M. Beatty, A. Gómez and $\mathrm{R}$. McCulloch provided technical assistance. This work was funded by an NSERC research grant to RKP.

AceñolazA, F.G. and Buators, L.A. 1993. Nonmarine perigondwanic trace fossils from the late Paleozoic of Argentina. Ichnos, 2, pp. 183-201.

Anderson, A.M. 1975. The "trilobite" trackways in the Table Mountain Group (Ordovician) of South Africa. Palaeontologia africana, 18 , pp. $35-45$.

Archer, A.W., CAlder, J.H., Gibling, M.R., Naylor, R.D., Reid, D.R., and WightMAN, W.G. 1995. Invertebrate trace fossils and agglutinated foraminifera as indicators of marine influence within the classic Carboniferous section at Joggins, Nova Scotia, Canada. Canadian Journal of Earth Sciences, 32, pp. 2027-2039.

BAIRD, D. and CARROLL, R.L. 1967. Romeriscus, the oldest known reptile. Science, 157 , pp. 56-59.

Bergstrom, J. 1976. Lower Palaeozoic trace fossils from eastern Newfoundland. Canadian Journal of Earth Sciences, 13, pp. 1613-1633.

Birkenmajer, K. and Bruton, D.L. 1971. Some trilobite resting and crawling traces. Lethaia, 4, pp. 303-319.

Boyd, D.W. and LOOPE, D.B. 1984. Probable vertebrate origin for certain sole marks in Triassic red beds of Wyoming. Journal of Paleontology, 58, pp. 467-476.

BRADY, L.F. 1947. Invertebrate tracks from the Coconino Sandstone of northern Arizona. Journal of Paleontology, 21, pp. 466-472.

1949. Oniscoidichnus, new name for Isopodichnus Brady 1947, not Bornemann 1889. Journal of Paleontology, 23, p. 573.

Brand, L. 1979. Field and laboratory studies on the Coconino Sandstone (Permian) vertebrate footprints and their paleoecological implications. Palaeogeography, Palaeoclimatology, Palaeoecology, 28, pp. 25-38.

1996. Variations in salamander trackways resulting from substrate differences. Joumal of Paleontology, 70, pp. 10041010.

Briggs, D.E.G., Puint, A.G., and Pickerill, R.K. 1984. Arthropleura trails from the Westphalian of eastern Canada. Palaeontology, 27, pp. 843-855.

Bromley, RG. and AsGaARD, U. 1979. Triassic freshwater ichnocoenoses from Carlsberg Fjord, east Greenland. Palaeogeography, Palaeoclimatology, Palaeoecology, 28, pp. 39-80.

Buatois, L.A. and Mangano, M.G. 1993. Trace fossils from a Carboniferous turbiditic lake: implications for the recognition of additional nonmarine ichnofacies. Ichnos, 2, pp. $237-$ 258.

CAster, K.E. 1939. Were Micrichnus scotti Abel and Artiodactylus sinclairi Abel of the Newark Series (Triassic) made by vertebrates or limuloids? American Journal of Science, 237, pp. 786-797.

Clarkson, E.N.K. 1993. Invertebrate Palaeontology and Evolution. 3rd Edition. Chapman and Hall, London, 434 p.

CrImEs, T.P. 1970. Trilobite tracks and other trace fossils from the Upper Cambrian of North Wales. Geological Journal, 7, pp. 47-68. 
Table 5. Trackways recorded from Carboniferous nonmarine strata of the Maritimes.

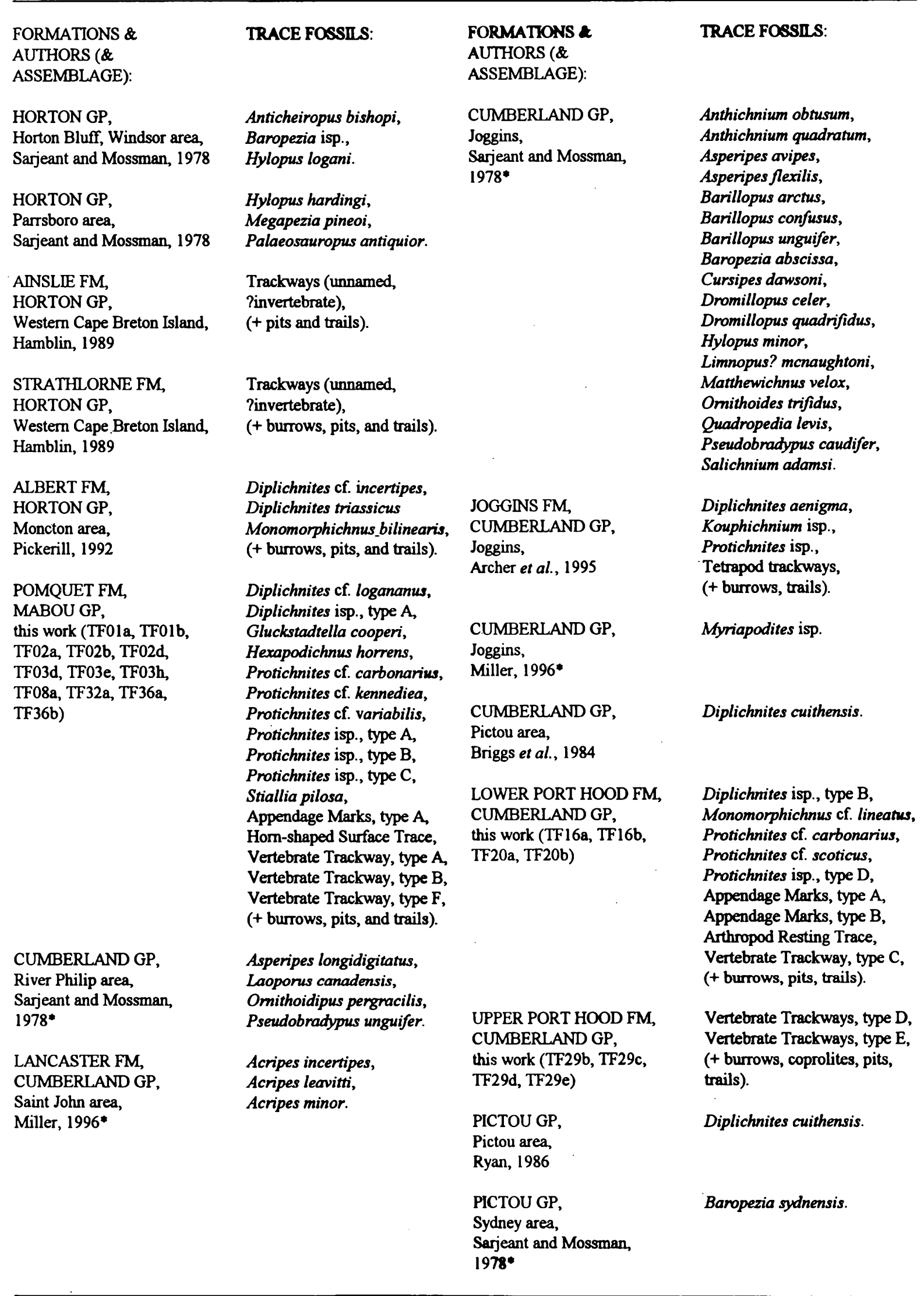

* Syntheses of earlier works 
Crimes, T.P., LegG, I., Marcos, A., and Arboleya, M. 1977. ?Late Precambrian-low Lower Cambrian trace fossils from Spain. In Trace Fossils 2. Edited by T.P. Crimes and J.C. Harper. Seel House Press, Liverpool, pp. 91-138.

Dawson, J.W. 1862. Notice on the discovery of additional remains of land animals in the coal measures of the south Joggins, Nova Scotia. Quarterly Journal of the Geological Society [London], 18 , pp. 5-7.

- 1873. Impressions and footprints of aquatic animals and imitative markings on Carboniferous rocks. American Journal of Science, 105, pp. 16-24.

Demathieu, G., Gand, G., and Toutin-Morin, N. 1992. La palichnofaune des bassins Permiens Provençaux. Géobios, 25, pp. 19-54.

Dias-Fabricio, M.E. and Guerra-Sommer, M. 1989. Síntese dos estudos ichnológicos do Grupo Itararé no Rio Grande do Sul. Pesqisas, 22, pp. 71-88.

Fillion, D. and Pickerill, R.K. 1990. Ichnology of the Upper Cambrian? to Lower Ordovician Bell Island and Wabana groups of eastem Newfoundland, Canada. Palaeontographica Canadiana, 7, $119 \mathrm{p}$.

Fischer, W.A. 1978. The habitat of the early vertebrates: trace and body fossil evidence from the Harding Formation (Middle Ordovician), Colorado. The Mountain Geologist, 15, pp. 126.

FOrsich, F.T. 1974. Ichnogenus Rhizocorallium. Palăontologische Zeitschrift, 48, pp. 16-28.

Glaessner, M.F. 1957. Palaeozoic arthropod trails from Australia. Paläontologische Zeitschrift, 31, pp. 103-109.

Goldring, R. and Seilacher A. 1971. Limulid undertracks and their sedimentological implications. Neues Jahrbuch furr Geologie und Palăontologie, Abhandlungen, 137, pp. 422-442.

Goldring, R., Pollard, J.E., and Taylor, A.M. 1997. Naming trace fossils. Geological Magazine, 134, pp. 265-268.

Hamblin, A.P. 1989. Sedimentology, tectonic control, and resource potential of the Upper Devonian-Lower Carboniferous Horton Group, Cape Breton Island, Nova Scotia. Unpublished PhD thesis, University of Ottawa, Ottawa, Canada, $300 \mathrm{p}$.

HÃntzschel, W. 1962. Trace fossils and problematica. In Treatise on Invertebrate Paleontology, Part W. Edited by R.C. Moore. Geological Society of America and University of Kansas Press, New York and Lawrence, Kansas, pp. W178-W245.

- 1975. Trace fossils and problematica. In Treatise on Invertebrate Paleontology, Part W. Miscellanea, Supplement 1. Series edited by C. Teichert. Geological Society of America and University of Kansas Press, Boulder, Colorado, and Lawrence, Kansas, pp. W1-W269.

Hardy, P.G. 1970. New Xiphosurid trails from the Upper Carboniferous of northern England. Palaeontology, 13, pp. 188190.

HARKNESS, R. 1856. On the lowest sedimentary rocks of the south of Scotland. Proceedings of the Geological Society [London], 12, pp. 238-245.

Haubold, H. 1970. Versuch einer Revision der Amphibien-Făhrten des Karbon und Perm. Freiberger Forschungschefte, 260, pp. 83-117.

Haubold, H. and Katzung, G. 1978. Palaeoecology and palaeoenvironments of tetrapod footprints from the Rotliegend (Lower Permian) of central Europe. Palaeogeography, Palaeoclimatology, Palaeoecology, 23, pp. 307-323.

Hгтснсоск, E. 1837. Fossil footsteps in sandstone and greywacke. Sillimans Journal [American Journal of Science], 32, pp. 174176.

1858. Ichnology of New England. A report on the sandstone of the Connecticut Valley, especially its footprints. W. White, Boston, 220 p.
1865. Supplement of the ichnology of New England. Wright and Porter, Boston, $96 \mathrm{p}$.

HoluB, V. and Kozur, H. 1981. Arthropodenfahrten aus dem Rotliegenden der CSSR. Geologie und Paläontologie Mitteilungen Innsbruck, 11 , pp. 95-148.

International Commission on Zoological Nomenclature (I.C.Z.N.). 1985. International Code of Zoological Nomenclature. (3rd edition Adopted by the 20th General Assembly of the International Union of Biological Sciences, 1985). International Trust for Zoological Nomenclature in association with the British Museum (Natural History), London, and University of California Press, Berkeley and Los Angeles, $338 \mathrm{p}$.

JARZEMBowski, E.A. 1989. Writhlington nature reserve. Proceedings of the Geologists' Association, 100, pp. 219-234.

Keighley, D.G. and Pickerill, R.K. 1996a. The evolution of fluvial systems in the Port Hood Formation (Upper Carboniferous), western Cape Breton Island, eastern Canada. Sedimentary Geology, 106, pp. 97-144.

-1996b. Ichnotaxonomic revision and the importance of type material -an alternative view. Palaeontology Newsletter, 32, pp. 8-12.

1996c. Small compound Cruziana, Rusophycus, and related ichnotaxa: the nomenclatural debate and systematic ichnology, with examples from eastern Canada. Ichnos, 4, pp. 261-285.

1997. Systematic ichnology of the Mabou and Cumberland groups (Carboniferous) of western Cape Breton Island, eastern Canada, 1: burrows, pits, trails, and coprolites. Atlantic Geology, 33, pp. 181-215.

LEONARDI, G. 1987. Glossary and Manual of Tetrapod Footprint Palaeoichnology. Departamento Nacional da Produção Mineral, Brasilia, Brazil, 75 p.

Linck, O. 1949. Lebens-Spuren aus dem Schilfsandstein (Mittl. Keuper km 2) NW-Württembergs und ihre Bedeutung fur die Bildungsgeschichte der Stufe. Jahreshefte des Vereins für vaterländische Naturkunde in Württemberg 97-101, pp. 1100.

LuLl, R.S. 1915. Triassic life of the Connecticut valley. State of Connecticut Geological and Natural History Survey Bulletin, 24, pp. 1-285.

1953. Triassic life of the Connecticut valley. State of Connecticut Geological and Natural History Survey Bulletin, 81, pp. 1-331.

MacNaughton, R.B. and Pickerill, R.K. 1995. Invertebrate ichnology of the nonmarine Lepreau Formation (Triassic), southern New Brunswick, eastern Canada. Journal of Paleontology, 69, pp. 160-171.

MAGwOoD, J.P.A. 1992. Ichnotaxonomy: a burrow by any other name...? In Trace Fossils. Edited by C.G. Maples and R.R. West. The Paleontological Society Short Courses in Paleontology, 5, pp. 15-33.

Marsh, O.C. 1869. Description of a new species of Protichnites from the Potsdam Sandstone of New York. American Journal of Science, 98 , pp. 46-49.

Matrhew, G.F. 1904. Note on the genus Hylopus of Dawson. Bulletin of the Natural History Society of New Brunswick, 5, pp. 247-252.

1905. New species and a new genus of Batrachian footprints of the Carboniferous system in eastern Canada. Proceedings and Transactions of the Royal Society of Canada, Series 2, 10, pp. 77-122.

- 1910. Remarkable forms of the Little River Group. Proceedings and Transactions of the Royal Society of Canada, Series 3, 3, pp. 115-125.

McKeever, P.J. and Haubold, H. 1996. Reclassification of vertebrate trackways from the Permian of Scotland and related 
forms from Arizona and Germany. Journal of Paleontology, 70, pp. 1011-1022.

MiLleR, R.F. 1996. Location of trace fossils and problematica of George Frederic Matthew from Part W, Treatise on Invertebrate Paleontology. Journal of Paleontology, 70, pp. 169171.

MiLLeR, M.F. and KNox, L.W. 1985. Biogenic structures and depositional environments of a Lower Pennsylvanian coal-bearing sequence, northern Cumberland Plateau, Tennessee, U.S.A. In Biogenic Structures: Their Use in Interpreting Depositional Environments. Edited by H.A. Curran. Society of Economic Paleontologists and Mineralogists Special Publication 35, pp. 6797.

Nielsen, E. 1949. On some trails from the Triassic beds of East Greenland. Meddelelser om Gronland, 149, 44 p.

Nopsca, F.B. 1923. Die Familien der Reptilien. Fortschritte der Geologie und Palaeontologie, 2, 210 p.

OppeL, A. 1862. Ueber Fahrten im lithographischen Schiefer (Ichnites lithographicus). Paläontologische Mittheilungen aus dem Museum des Kongiglich Bayerischen Staates, 1, pp. 121-125.

Osgood, R.G. and Drennan, W.T. 1975. Trilobite trace fossils from the Clinton Group (Silurian) of east-central New York State. Bulletins of American Paleontology, 67, pp. 299-348.

OWEN, R. 1852. Description of the impressions and footprints of the Protichnites from the Potsdam sandstone of Canada. Quarterly Journal of the Geological Society [London], 8, pp. 214-225.

Packard, A.S. 1900a. View of the Carboniferous fauna of the Narragansett Basin. Proceedings of the American Academy of Arts and Science, 35, pp. 399-405.

$1900 \mathrm{~b}$. On supposed merostomatous and other Paleozoic arthropod trails, with notes on those of Limulus. Proceedings of the American Academy of Arts and Science, 36, pp. 6371.

Pickerill, R.K. 1992. Carboniferous nonmarine invertebrate ichnocoenoses from southern New Brunswick, eastern Canada. Ichnos, 2, pp. 21-35.

1994. Nomenclature and taxonomy of invertebrate trace fossils. In The Palaeobiology of Trace Fossils. Edited by S.K. Donovan. John Wiley and Sons, Chichester, pp. 3-42.

Pickerill, R.K. and Keighley, D.G. 1997. Notostracan trackways and parataxonomy -a commentary. Acta Palaeontologica Polonica, 42, pp. 171-174.

Pollard, J.E. 1985. Isopodichnus, related arthropod trace fossils and notostracans from Triassic fluvial sediments. Transactions of the Royal Society of Edinburgh, Earth Sciences, 76, pp. 273-285.

Pollard, J.E. and Walker, E.F. 1984. Reasessment of sediments and trace fossils from Old Red Sandstone (Lower Devonian) of Dunure, Scotland, described by John Smith (1909). Géobios, 17, pp. 567-576.

Ryan, R.J. 1986. Fossil myriapod trails in the Permo-Carboniferous strata of northern Nova Scotia, Canada. Maritime Sediments and Atlantic Geology, 22, pp. 156-161.

Romano, M. and Whyte, M.A. 1987. A limulid trace fossil from the Scarborough Formation (Jurassic) of Yorkshire: its occurrence, taxonomy and interpretation. Proceedings of the Yorkshire Geological Society, 46, pp. 85-95.

Sarjeant, W.A.S. 1975. Fossil tracks and impressions of vertebrates. In The Study of Trace Fossils. Edited by R.W. Frey. Springer Verlag, New York, pp. 283-324.
1990. A name for the trace of an act: approaches to the nomenclature and classification of fossil vertebrate footprints. In Dinosaur Systematics: Approaches and Perspectives. Edited by K. Carpenter and P.J. Currie. Cambridge University Press, Cambridge, pp. 299-307.

Sarjeant, W.A.S. and Kennedy, W.J. 1973. Proposal of a code for the nomenclature of trace fossils. Canadian Journal of Earth Sciences, 10, pp. 460-475.

Sarjeant, W.A.S. and Mossman, D.J. 1978. Vertebrate footprints from the Carboniferous sediments of Nova Scotia: a historical review and description of newly discovered forms. Palaeogeography, Palaeoclimatology, Palaeoecology, 23, pp. 279-306.

Savage, N.M. 1971. A varvite ichnocoenosis from the Dwyka series of Natal. Lethaia, 4, pp. 217-233.

Seilacher, A. 1955. Spuren und Lebensweise der Trilobiten. In Beitrăge zur Kenntnis des Kambriums in der Salt Range (Pakistan). Edited by O.H. Schindewolf and A. Seilacher. Abhandlungen der mathematisch-naturwissenschaftlichen Klasse, Akademie der Wissenschaften und der Literatur in Mainz, 10, pp. 342 372.

1963. Lebensspuren und Salinitätsfazies. Fortschritte in der Geologie von Rheinland und Westfalens, 10, pp. 81-94.

1964. Biogenic sedimentary structures. In Approaches to Paleoecology. Edited by J. Imbrie and N. Newell. Wiley, New York, pp. 296-316.

1967. Bathymetry of trace fossils. Marine Geology, 5, pp. 413-428.

SMITH, J. 1909. Upland fauna of the Old Red Sandstone Formation of Carrick, Ayrshire. A.W. Cross, Kilwinning, Scotland, 41 p.

Stanley, D.C.A. and Pickerill, R.K. 1998. Systematic ichnology of the late Ordovician Georgian Bay Formation of southern Ontario, eastern Canada. Royal Ontario Museum, Life Science Contributions, 162, $55 \mathrm{p}$.

Sterngerg, C.M. 1933. Carboniferous tracks from Nova Scotia. Geological Society of America Bulletin, 44, pp. 951-964.

Størmer, L. 1934. Downtonian Merostomata from Spitsbergen, with remarks on the suborder Synziphosura. Skrifter utgitt av det Norske Videnskaps-Akademi i Oslo, I. MatematiskNaturvidenskapelig Klasse 1934, 3, 26 p.

Sutcliffe, O.E. 1997. An ophiuroid trackway from the Lower Devonian Hunsrulck Slate, Germany. Lethaia, 30, pp. 33-39.

TREwin, N.H. 1994. A draft system for the identification and description of arthropod trackways. Palaeontology, 37, pp. 811-823.

WALKER, E.F. 1985. Arthropod ichnofauna of the Old Red Sandstone at Dunure and Montrose, Scotland. Transactions of the Royal Society of Edinburgh, Earth Sciences, 76, pp. 287297.

Walter, H. 1983. Zur Taxonomie, Ökologie und Biostratigraphie der Ichnia limnischterrestrischer Arthropoden des mitteleuropäischen Jungpaläozoikums. Freiberger Forschungshefte, C382, pp. 146-193.

1986. Beiträge zur Ichnologie limnisch-terrestrischer Sedimentationsräume, Teil I: Zur Verbreitung von Acripes MATTHEW 1910 und Assoziationen von Arthropodenfahirten im Oberkarbon und Perm. Freiberger Forschungschefte, C410, pp. 5-12. 